\title{
Article \\ Improving Bridge Expansion and Contraction Installation Replacement Decision System Using Hybrid Chaotic Whale Optimization Algorithm
}

\author{
Zian Xu (D) and Minshui Huang *(1) \\ School of Civil Engineering and Architecture, Wuhan Institute of Technology, Wuhan 430073, China; \\ xuzian@wit.edu.cn \\ * Correspondence: huangminshui@tsinghua.org.cn
}

check for updates

Citation: Xu, Z.; Huang, $\mathrm{M}$. Improving Bridge Expansion and Contraction Installation Replacement Decision System Using Hybrid Chaotic Whale Optimization Algorithm. Appl. Sci. 2021, 11, 6222. https://doi.org/10.3390/app11136222

Academic Editor: Mariusz Szóstak

Received: 18 June 2021

Accepted: 1 July 2021

Published: 5 July 2021

Publisher's Note: MDPI stays neutra with regard to jurisdictional claims in published maps and institutional affiliations.

Copyright: (c) 2021 by the authors. Licensee MDPI, Basel, Switzerland. This article is an open access article distributed under the terms and conditions of the Creative Commons Attribution (CC BY) license (https:// creativecommons.org/licenses/by/ $4.0 /)$.

\begin{abstract}
Bridge expansion and contraction installation (BECI) has proved to be an essential component of the bridge structure due to its stability, comfort, and durability benefits. At present, traditional replacement technologies for modular type, comb plate type, and seamless type BECIs are widely applied worldwide. Nevertheless, it is unfortunate that the research conducted on decision-making (DM) approaches for the technical condition assessment and the optimal replacement plan selection of existing BECIs remain scarce, which results in the waste of resources and the increase in cost. Therefore, a BECI technical condition assessment approach, which contains specific on-site inspection regulations with both qualitative and quantitative descriptions, is proposed in this research, and a corresponding calculation program has been developed based on the MATLAB platform, which provides the basis for the necessity of replacement. Simultaneously, the hybrid chaotic whale optimization algorithm is designed and performed to improve and automate the process of optimal replacement plan selection under the assistance of the analytic hierarchy process (AHP), where both the achievement in consistency modification and the reservation of initial information are perused, and its superiority and effectiveness are verified via the comparative experimental analysis. The improved BECI replacement decision system is established, and the corresponding case study demonstrates that the proposed system in this research proves reasonable and feasible. The improved system can effectively assist bridge managers in making more informed operation and maintenance $(\mathrm{O}$ and $\mathrm{M})$ decisions in actual engineering projects.
\end{abstract}

Keywords: bridge expansion and contraction installation (BECI); decision making (DM); technical condition assessment; analytic hierarchy process (AHP); whale optimization algorithm; Tent chaotic mapping; Lévy flight

\section{Introduction}

With the rapid increase in technical obstacles caused by the damage of bridge expansion and contraction installations (BECIs), related resources waste, economic burdens, traffic hazards, and social arguments have attracted considerable attention, which emphasizes the significance of systematic operation and maintenance $(\mathrm{O}$ and $\mathrm{M})$ for BECIs.

Accordingly, the replacement of BECI has played a crucial role in the field of bridge $\mathrm{O}$ and $\mathrm{M}$, where the decision making (DM) and optimization of the $\mathrm{O}$ and $\mathrm{M}$ plan are highly prized. In accordance with installation types and construction characteristics, the replacement technologies for BECIs can be generally divided into modular type replacement, comb plate type replacement, and seamless type replacement [1]. Referring to the research of Huang et al. [2], a BECI replacement decision system is established based on the analytic hierarchy process (AHP) [3], where the design requirements, construction requirements, management requirements, and scopes of application are integrated as decision criteria to provide a persuasive mathematical model for the selection of an optimal replacement plan. As a potential multi-criteria decision-making (MCDM) method, AHP has higher 
applicability and effectiveness compared with other common ones, such as the analytic network process (ANP), the preference ranking organization method for enrichment evaluations (PROMETHEE), and the simple additive weighting (SAW) [4]. Additionally, under the assistance of the Delphi method, which is capable of providing a strong basis for the construction of hierarchy model, the AHP is widely applied to evaluate the complexity of projects [5].

Nevertheless, the AHP is always confronted with the challenge of consistency test due to massive decision criteria. In many studies, the framework of AHP consistency modification is usually divided into two stages. Initially, a mathematical model for modification is established in accordance with the characteristics of comparison matrices, where the least square method is effectively employed [6,7], and the iterative algorithm is designed and performed to handle it subsequently [8]. Similarly, much research has been conducted successfully in such a framework based on the meta-heuristic algorithms, such as particle swarm optimization (PSO) [9], genetic algorithm (GA) [10], and ant colony optimization (ACO) [11], where the modification method proves reasonable and feasible and could also be extended to multiple engineering optimization problems [12-14].

Derived from the bubble-net hunting behavior of humpback whales, the whale optimization algorithm (WOA) [15] was proposed as a meta-heuristic algorithm to handle optimization problems in 2016. As an emerging and prevailing meta-heuristic algorithm, the superiority and effectiveness of WOA are verified by being tested with 29 mathematical optimization problems and six structural design problems [16], which leads to the wide application of WOA in engineering optimization problems, such as electrical engineering, civil engineering, classification, clustering, image processing, mechanical engineering, control engineering, robot path, networks, industrial engineering, task scheduling, and other engineering applications [17-28]. However, similarly to other meta-heuristic algorithms, the WOA is confronted with the problem of slow convergence speed, which motivates chaos theory to be introduced into the WOA optimization process, and the results prove that the chaotic mappings are capable of enhancing the performance of WOA, especially Tent chaotic mapping [29]. Originally, the Lévy flight strategy was introduced to develop the cuckoo search (CS) algorithm, which is a specific class of random walk in which the step lengths are distributed based on a heavy power law tails, and it proves efficient to assist the algorithm to perform a global search [30,31]. In order to improve the global search performance of WOA, a set of studies has been conducted on the hybridization of WOA and Lévy flight [32-34], where the results demonstrate that this strategy can effectively enhance the convergence accuracy, speed, and stability of WOA, even to handle a large-scale global optimization problem.

Much research has been conducted on decision making and plan optimization, whose achievements play a significant guiding role in later study and production. However, to date, the existing developed system utilized in decision making for BECI replacement remains insufficient to handle the large-scale MCDM optimization problem. Meanwhile, the approach of technical condition assessment of BECIs is constrained by the lack of on-site inspection regulations, which brings technical obstacles to the actual operation, and thus, motivates this article. Furthermore, the significance of automation in the DM system should never be ignored.

Based on the results of existing research, a BECI technical condition assessment approach, which contains specific on-site inspection regulations with both qualitative and quantitative descriptions, is proposed in this research, and a corresponding calculation program is developed based on the MATLAB platform, which provides the basis for the necessity of replacement. Simultaneously, the hybrid chaotic whale optimization algorithm is designed and performed to improve and automate the process of optimal replacement plan selection under the assistance of the analytic hierarchy process (AHP), where both the achievement in consistency modification and the reservation of initial information are perused, and its superiority and effectiveness are verified via the comparative experimental analysis. Consequently, a performance-based optimal replacement plan is selected by 
the improved decision system to guide later bridge managers, which also promotes the application of computer science technologies in the field of bridge $\mathrm{O}$ and $\mathrm{M}$.

\section{Objective}

The improved BECI replacement decision system established in this article is aimed at achieving the objectives of two aspects, namely, realizing the standardization of BECI on-site inspection and the automations of both the technical condition assessment and the replacement plan selection. Accordingly, the proposed decision system can be divided into two stages, as illustrated in Figure 1.

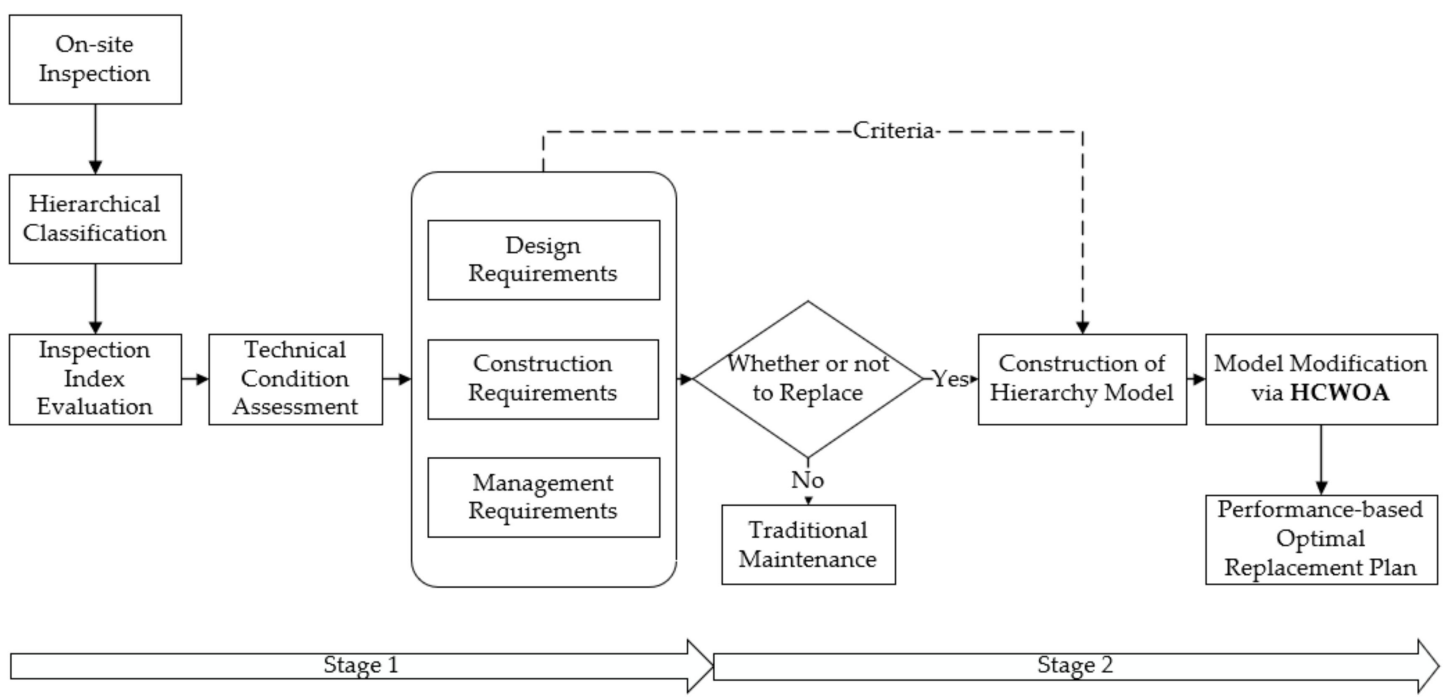

Figure 1. Framework of improved BECI replacement decision system.

Stage 1: Technical condition assessment. The on-site inspection is conducted on the target BECI, which will be hierarchically classified according to various installation types. The inspection index evaluation is performed to provide the basis of progressive assessment calculation, and "whether or not to replace" is determined.

Stage 2: Selection of replacement plan based on HCWOA. Twelve kinds of design, construction, and management requirements are introduced as the decision criteria, where the hierarchy model for selecting the performance-based optimal replacement plan is constructed via AHP. The HCWOA is designed and utilized to modify and handle the proposed mathematical model, where the optimal plan is selected precisely.

\section{Methodology}

\subsection{Technical Condition Assessment}

First and foremost, in order to provide a basis for the necessity of BECI replacement, the technical condition assessment should be performed. In the light of the transportation industry standard of the People's Republic of China [35,36], the framework of the BECI technical condition assessment approach is established and demonstrated in Figure 2.

\subsubsection{Hierarchical Classification}

In terms of the design mentality of this method, hierarchical classification is conducted after the on-site inspection to divide the inspected BECI into three layers from top to bottom: main structure and accessory structure; components; members. Referring to related standards of the transportation industry of the People's Republic of China [1], 6 kinds of modular type, comb plate type, and seamless type BECIs are introduced to this method as specific assessment objects, which are widely applied worldwide. The hierarchical classification of BECIs is shown in Table 1. 


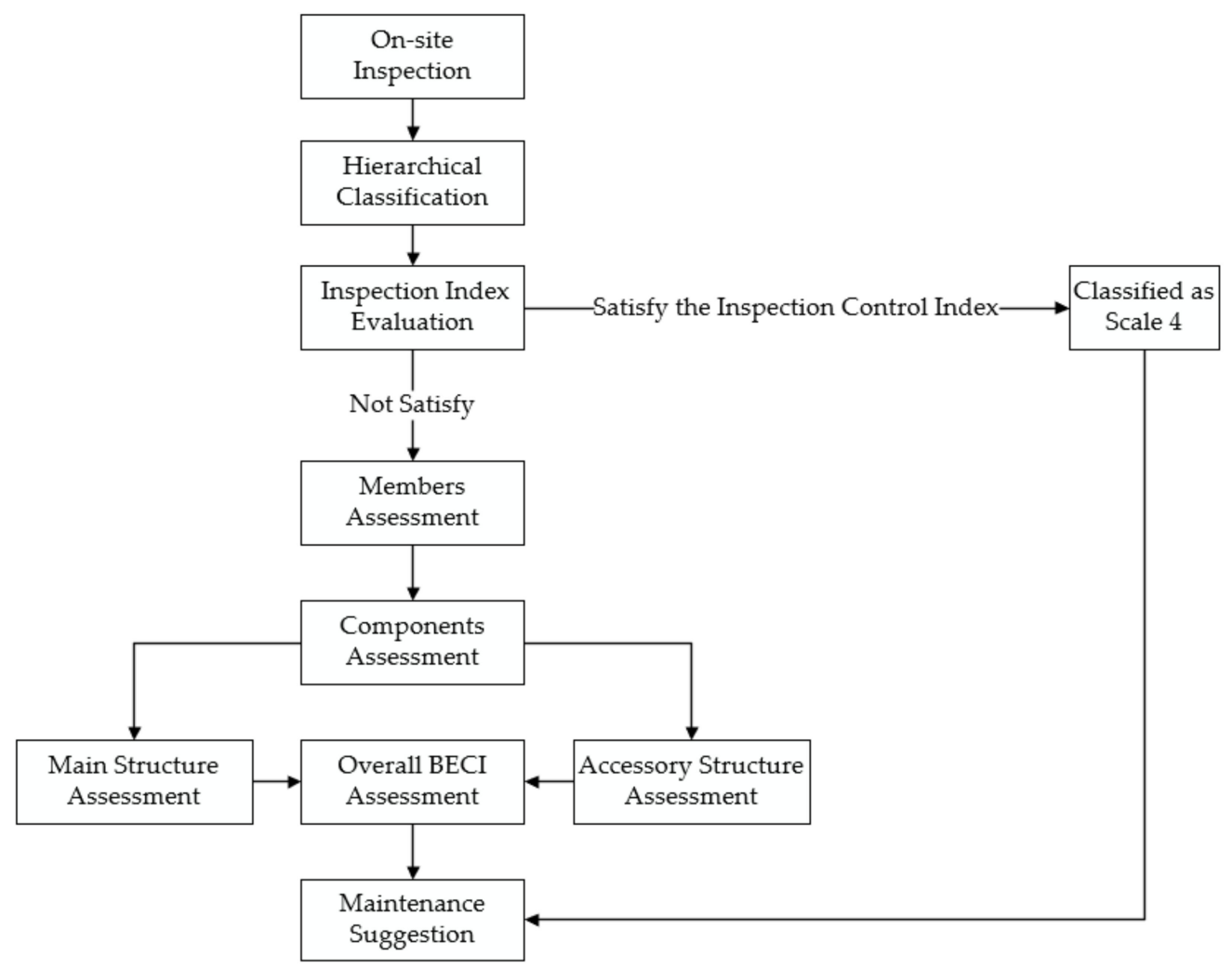

Figure 2. Framework of BECI technical condition assessment.

Table 1. Hierarchical classification of BECIs.

\begin{tabular}{|c|c|c|c|c|}
\hline Installation & Part & No. & Component & Quantity of Members \\
\hline \multirow{3}{*}{$\begin{array}{c}\text { MA } \\
\text { Modular type }\end{array}$} & Main structure & 1 & Side beam & 2 \\
\hline & & 2 & Anchorage concrete & 2 \\
\hline & Accessory structure & 3 & Rubber sealing tape & 1 \\
\hline \multirow{7}{*}{$\begin{array}{c}\text { MB } \\
\text { Modular type }\end{array}$} & Main structure & 1 & Side beam & 2 \\
\hline & & 2 & Intermediate beam & Quantity of intermediate beams \\
\hline & & 3 & Bearing system & Quantity of support beams \\
\hline & & 4 & Displacement control system & 1 \\
\hline & & 5 & Elastic support & 1 \\
\hline & & 6 & Anchorage concrete & 2 \\
\hline & Accessory structure & 7 & Rubber sealing tape & Quantity of intermediate beams +1 \\
\hline \multirow{4}{*}{$\begin{array}{c}\text { SC } \\
\text { Comb plate type }\end{array}$} & Main structure & 1 & Comb plate & Quantity of comb plate units \\
\hline & & 2 & Anchor bolt & Quantity of comb plate units \\
\hline & & 3 & Anchorage concrete & 2 \\
\hline & Accessory structure & 4 & Drainage device & 1 \\
\hline \multirow{7}{*}{$\begin{array}{c}\text { SSA, SSB } \\
\text { Comb plate type }\end{array}$} & Main structure & 1 & Fixed comb plate & Quantity of fixed comb plate units \\
\hline & & 2 & Movable comb plate & Quantity of movable comb plate units \\
\hline & & 3 & Stainless steel sliding plate & Quantity of comb plate units \\
\hline & & 4 & Anchor bolt & Quantity of comb plate units \\
\hline & & 5 & Multidirectional displacement device & Quantity of movable comb plate units \\
\hline & & 6 & Anchorage concrete & 2 \\
\hline & Accessory structure & 7 & Drainage device & 1 \\
\hline \multirow{4}{*}{ Seamless type } & Main structure & 1 & Elastic expansion body & 1 \\
\hline & Accessory structure & 2 & Steel cover plate & 1 \\
\hline & & 3 & Nail & 1 \\
\hline & & 4 & Foam plate & 1 \\
\hline
\end{tabular}




\subsubsection{Inspection Index Evaluation}

Subsequently, in the process of on-site inspection, inspectors are also required to evaluate the inspection indices of each member. Therefore, a standardized inspection index evaluation approach of BECIs with both specific qualitative and quantitative regulations are proposed for the determination of inspection index scale. Corresponding to various types of BECIs, the regulations of inspection index evaluation are shown in Tables 2-6, respectively. In particular, the scale will be defined as 1 when the technical condition of inspection index remains excellent.

Table 2. Inspection index evaluation of the BECI of MA modular type.

\begin{tabular}{|c|c|c|c|c|}
\hline Inspection Object & Inspection Index & Scale & Qualitative Description & Quantitative Description \\
\hline \multirow{6}{*}{ Side beam } & \multirow{3}{*}{ Evenness } & 2 & Slightly uneven & Elevation difference $\leq 10 \mathrm{~mm}$ \\
\hline & & 3 & Obviously uneven, local fractures occur & $10 \mathrm{~mm}<$ elevation difference $\leq 30 \mathrm{~mm}$ \\
\hline & & 4 & $\begin{array}{l}\text { Excessively uneven, vehicle bumping, and } \\
\text { side sinking occur }\end{array}$ & Elevation difference $>30 \mathrm{~mm}$ \\
\hline & \multirow{3}{*}{ Spacing } & 2 & Slightly narrow & $50 \mathrm{~mm}<$ spacing $\leq$ design value \\
\hline & & 3 & Obviously narrow & $10 \mathrm{~mm}<$ spacing $\leq 50 \mathrm{~mm}$ \\
\hline & & 4 & Excessively narrow or wide & $\begin{array}{l}\text { Spacing }>\text { design value, } \\
\text { or spacing } \leq 10 \mathrm{~mm}\end{array}$ \\
\hline \multirow{3}{*}{ Anchorage concrete } & \multirow{3}{*}{ Fracture } & 2 & Local fractures occur & $\begin{array}{c}\text { Fractures } \leq 3, \text { fracture width } \leq 2 \mathrm{~mm}, \\
\text { damaged area } \leq 10 \% \text { anchorage } \\
\text { concrete area }\end{array}$ \\
\hline & & 3 & Multiple fractures occur & $\begin{array}{c}3<\text { fractures } \leq 5, \\
2 \mathrm{~mm}<\text { fracture width } \leq 10 \mathrm{~mm}, \\
10 \%<\text { damaged area } \leq 20 \% \text { anchorage } \\
\text { concrete area }\end{array}$ \\
\hline & & 4 & $\begin{array}{l}\text { Serious fractures occur, anchorage function } \\
\text { fails }\end{array}$ & $\begin{array}{c}\text { Fractures }>5, \\
\text { fracture width }>10 \mathrm{~mm}, \\
\text { damaged area }>20 \% \text { anchorage } \\
\text { concrete area }\end{array}$ \\
\hline \multirow{3}{*}{ Rubber sealing tape } & \multirow{3}{*}{ Aging } & 2 & Slightly aging, local fractures occur & \multirow{3}{*}{ 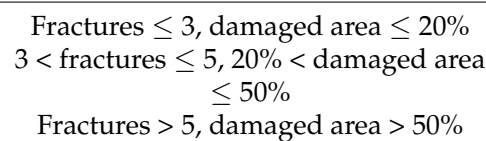 } \\
\hline & & 3 & Obviously aging, multiple fractures occur & \\
\hline & & 4 & Excessively aging, serious fractures occur & \\
\hline
\end{tabular}

Table 3. Inspection index evaluation the BECI of MB modular type.

\begin{tabular}{|c|c|c|c|c|}
\hline Inspection Object & Inspection Index & Scale & Qualitative Description & Quantitative Description \\
\hline \multirow{6}{*}{$\begin{array}{l}\text { Side beam, } \\
\text { intermediate beam }\end{array}$} & \multirow{3}{*}{ Evenness } & 2 & Slightly uneven & Elevation difference $\leq 15 \mathrm{~mm}$ \\
\hline & & 3 & Obviously uneven, local fractures occur & $15 \mathrm{~mm}<$ spacing $\leq 30 \mathrm{~mm}$ \\
\hline & & 4 & $\begin{array}{l}\text { Excessively uneven, vehicle bumping, and } \\
\text { side sinking occur }\end{array}$ & $30 \mathrm{~mm}<$ spacing $\leq 100 \mathrm{~mm}$ \\
\hline & \multirow{3}{*}{ Spacing } & 2 & Slightly narrow & $50 \mathrm{~mm}<$ spacing $\leq$ design value \\
\hline & & 3 & Obviously narrow & $10 \mathrm{~mm}<$ spacing $\leq 50 \mathrm{~mm}$ \\
\hline & & 4 & Excessively narrow or wide & $\begin{array}{c}\text { Spacing }>\text { design value, or spacing } \\
\leq 10 \mathrm{~mm}\end{array}$ \\
\hline \multirow{3}{*}{ Bearing system } & \multirow{3}{*}{$\begin{array}{l}\text { Bolt looseness, hanger } \\
\text { damage }\end{array}$} & 2 & $\begin{array}{l}\text { Local anchor bolts are unfixed, local hanger } \\
\text { damages occur }\end{array}$ & $\begin{array}{c}\text { Proportion of unfixed bolts } \leq 10 \% \text {, or } \\
1 \text { hanger damage }\end{array}$ \\
\hline & & 3 & $\begin{array}{l}\text { Multiple anchor bolts are unfixed, multiple } \\
\text { hanger damages occur }\end{array}$ & $\begin{array}{c}10 \%<\text { proportion of unfixed bolts } \leq \\
30 \% \text {, or } 2 \text { hanger damages }\end{array}$ \\
\hline & & 4 & $\begin{array}{c}\text { Massive anchor bolts are unfixed, massive } \\
\text { hanger damages occur }\end{array}$ & $\begin{array}{l}\text { Proportion of unfixed bolts }>30 \% \text {, or } \\
\text { hanger damages }>2\end{array}$ \\
\hline \multirow{3}{*}{$\begin{array}{l}\text { Displacement control } \\
\text { system }\end{array}$} & \multirow{3}{*}{$\begin{array}{l}\text { Spring deformation, } \\
\text { bolt looseness, hinge } \\
\text { damage }\end{array}$} & 2 & $\begin{array}{l}\text { Serious spring deformations occur, local } \\
\text { bolts are unfixed, local hinges are damaged }\end{array}$ & $\begin{array}{c}\text { Spring deformation }>20 \% \text { design } \\
\text { value, or proportion of unfixed bolts } \leq \\
10 \% \text {, or } 1 \text { hinge damage }\end{array}$ \\
\hline & & 3 & $\begin{array}{l}\text { Local springs are damaged, multiple bolts } \\
\text { are unfixed, multiple hinges are damaged }\end{array}$ & $\begin{array}{c}\text { Proportion of damaged springs } \leq 10 \% \text {, } \\
\text { or } 10 \%<\text { proportion of unfixed bolts } \leq \\
30 \% \text {, or } 2 \text { hinge damages }\end{array}$ \\
\hline & & 4 & $\begin{array}{c}\text { Multiple springs are damaged, massive } \\
\text { bolts are unfixed, massive hinges are } \\
\text { damaged }\end{array}$ & $\begin{array}{c}\text { Proportion of damaged springs } 10 \% \text {, or } \\
\text { proportion of unfixed bolts }>30 \% \text {, or } \\
\text { hinge damages }>2\end{array}$ \\
\hline
\end{tabular}


Table 3. Cont.

\begin{tabular}{|c|c|c|c|c|}
\hline Inspection Object & Inspection Index & Scale & Qualitative Description & Quantitative Description \\
\hline \multirow{3}{*}{ Elastic support } & \multirow{3}{*}{ Support deformation } & 2 & Slight support deformations occur & $\begin{array}{c}\text { Support deformations } \leq \text { allowable } \\
\text { value }\end{array}$ \\
\hline & & 3 & Obvious support deformations occur & $\begin{array}{c}\text { Support deformations > allowable } \\
\text { value }\end{array}$ \\
\hline & & 4 & Serious support deformations occur & Proportion of damaged supports $>30 \%$ \\
\hline \multirow{3}{*}{ Anchorage concrete } & \multirow{3}{*}{ Fracture } & 2 & Local fractures occur & $\begin{array}{c}\text { Fractures } \leq 3, \text { fracture width } \leq 2 \mathrm{~mm}, \\
\text { damaged area } \leq 10 \%\end{array}$ \\
\hline & & 3 & Multiple fractures occur & $\begin{array}{c}3<\text { tractures } \leq 5,2 \mathrm{~mm}<\text { fracture } \\
\text { width } \leq 10 \mathrm{~mm}, 10 \%<\text { damaged area } \\
\leq 20 \%\end{array}$ \\
\hline & & 4 & $\begin{array}{l}\text { Serious fractures occur, } \\
\text { anchorage function fails }\end{array}$ & $\begin{array}{c}\text { Fractures }>5 \text {, fracture width }>10 \mathrm{~mm}, \\
\text { damaged area }>20 \%\end{array}$ \\
\hline \multirow{3}{*}{ Rubber sealing tape } & \multirow{3}{*}{ Aging } & 2 & Slightly aging, local fractures occur & \multirow{3}{*}{$\begin{array}{c}\text { Fractures } \leq 3, \text { damaged area } \leq 20 \% \\
\begin{array}{c}3<\text { fractures } \leq 5,20 \%<\text { damaged area } \\
\leq 50 \% \\
\text { Fractures }>5, \text { damage area }>50 \%\end{array}\end{array}$} \\
\hline & & 3 & Obviously aging, multiple fractures occur & \\
\hline & & 4 & Excessively aging, serious fractures occur & \\
\hline
\end{tabular}

Table 4. Inspection index evaluation of the BECI of SC comb plate type BECI.

\begin{tabular}{|c|c|c|c|c|}
\hline Inspection Object & Inspection Index & Scale & Qualitative Description & Quantitative Description \\
\hline \multirow{3}{*}{ Comb plate } & \multirow{3}{*}{ Evenness } & 2 & Slightly uneven, local fractures occur & \multirow{3}{*}{$\begin{array}{c}\text { Damaged area } \leq 10 \%, 1 \mathrm{~mm}< \\
\text { elevation differences } \leq 2 \mathrm{~mm} \\
10 \%<\text { damaged area } \leq 30 \%, 2 \mathrm{~mm}< \\
\text { elevation differences } \leq 4 \mathrm{~mm} \\
\text { Damaged area }>30 \% \text {, elevation } \\
\text { differences }>4 \mathrm{~mm}\end{array}$} \\
\hline & & 3 & Obviously uneven, multiple fractures occur & \\
\hline & & 4 & $\begin{array}{l}\text { Seriously uneven, serious fractures } \\
\text { differences occur }\end{array}$ & \\
\hline \multirow{3}{*}{ Anchor bolt } & \multirow{3}{*}{ Looseness } & 2 & Local anchor bolts are unfixed & \multirow{3}{*}{$\begin{array}{c}\text { Proportion of damaged bolts } \leq 10 \% \\
10 \%<\text { proportion of damaged bolts } \leq \\
30 \% \\
\text { Proportion of damaged bolts }>30 \%\end{array}$} \\
\hline & & 3 & Multiple anchor bolts are unfixed & \\
\hline & & 4 & Massive anchor bolts are unfixed & \\
\hline \multirow{3}{*}{ Anchorage concrete } & \multirow{3}{*}{ Fracture } & 2 & Local fractures occur & \multirow{3}{*}{$\begin{array}{c}\text { Fractures } \leq 3, \text { fracture width } \leq 2 \mathrm{~mm}, \\
\text { damaged area } \leq 10 \% \text { anchorage } \\
\text { concrete area } \\
3<\text { fractures } \leq 5,2 \mathrm{~mm}<\text { fracture } \\
\text { width } \leq 10 \mathrm{~mm}, 10 \% \text { anchorage } \\
\text { concrete area }<\text { damaged area } \leq 20 \% \\
\text { anchorage concrete area } \\
\text { Fractures }>5 \text {, fracture width }>10 \mathrm{~mm}, \\
\text { damaged area }>20 \% \text { anchorage } \\
\text { concrete area }\end{array}$} \\
\hline & & 3 & Multiple fractures occur & \\
\hline & & 4 & $\begin{array}{l}\text { Serious fractures occur, anchorage function } \\
\text { fails }\end{array}$ & \\
\hline \multirow{3}{*}{ Drainage device } & \multirow{3}{*}{ Fracture } & 2 & Local fractures occur & \multirow{3}{*}{ 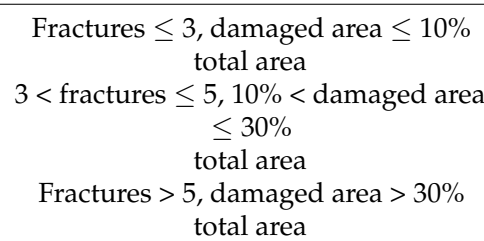 } \\
\hline & & 3 & Multiple fractures occur & \\
\hline & & 4 & Serious fractures occur & \\
\hline
\end{tabular}


Table 5. Inspection index evaluation of the BECI of SSA, SSB comb plate type.

\begin{tabular}{|c|c|c|c|c|}
\hline Inspection Object & Inspection Index & Scale & Qualitative Description & Quantitative Description \\
\hline \multirow{3}{*}{$\begin{array}{l}\text { Fixed comb plate, } \\
\text { movable comb plate }\end{array}$} & \multirow{3}{*}{ Evenness } & 2 & Slightly uneven, local fractures occur & $\begin{array}{l}\text { Damaged area } \leq 10 \%, 1 \mathrm{~mm}< \\
\text { elevation differences } \leq 2 \mathrm{~mm}\end{array}$ \\
\hline & & 3 & Obviously uneven, multiple fractures occur & $\begin{array}{c}10 \%<\text { damaged area } \leq 30 \%, 2 \mathrm{~mm}< \\
\text { elevation differences }<4 \mathrm{~mm}\end{array}$ \\
\hline & & 4 & $\begin{array}{l}\text { Seriously uneven, serious fractures } \\
\text { differences occur }\end{array}$ & $\begin{array}{c}\text { Damaged area }>30 \%, \text { elevation } \\
\text { differences }>4 \mathrm{~mm}\end{array}$ \\
\hline \multirow{3}{*}{$\begin{array}{l}\text { Stainless steel sliding } \\
\text { plate }\end{array}$} & \multirow{3}{*}{ Abrasion } & 2 & Local abrasions occur & \multirow{3}{*}{$\begin{array}{c}\text { Abrasion area } \leq 10 \% \text { total area } \\
10 \%<\text { abrasion area } \leq 30 \% \text { total area } \\
\text { Abrasion area }>30 \% \text { total area }\end{array}$} \\
\hline & & 3 & Multiple abrasions occur & \\
\hline & & 4 & Massive abrasions occur & \\
\hline \multirow{3}{*}{ Anchor bolt } & \multirow{3}{*}{ Looseness } & 2 & Local anchor bolts are unfixed & \multirow{3}{*}{$\begin{array}{c}\text { Proportion of damaged bolts } \leq 10 \% \\
10 \%<\text { proportion of damaged bolts } \leq \\
30 \% \\
\text { Proportion of damaged bolts }>30 \%\end{array}$} \\
\hline & & 3 & Multiple anchor bolts are unfixed & \\
\hline & & 4 & Massive anchor bolts are unfixed & \\
\hline \multirow{3}{*}{$\begin{array}{l}\text { Multidirectional } \\
\text { displacement device }\end{array}$} & \multirow{3}{*}{ Flexibility } & 2 & \multirow{3}{*}{$\begin{array}{l}\text { Individual unit is inflexible } \\
\text { Partial units are inflexible } \\
\text { Multiple units are inflexible, device } \\
\text { function fails }\end{array}$} & 1 inflexible unit \\
\hline & & 3 & & 2 inflexible units \\
\hline & & 4 & & Inflexible units $>2$ \\
\hline \multirow{3}{*}{ Anchorage concrete } & \multirow{3}{*}{ Fracture } & 2 & Local fractures occur & \multirow{3}{*}{$\begin{array}{c}\text { Fractures } \leq 3, \text { fracture width } \leq 2 \mathrm{~mm}, \\
\text { damaged area } \leq 10 \% \text { anchorage } \\
\text { concrete area } \\
3<\text { fractures } \leq 5,2 \mathrm{~mm}<\text { fracture } \\
\text { width } \leq 10 \mathrm{~mm}, 10 \% \text { anchorage } \\
\text { concrete area }<\text { damaged area } \leq 20 \% \\
\text { anchorage concrete area } \\
\text { Fractures }>5 \text {, fracture width }>10 \mathrm{~mm}, \\
\text { damaged area }>20 \% \text { anchorage } \\
\text { concrete area }\end{array}$} \\
\hline & & 3 & Multiple fractures occur & \\
\hline & & 4 & $\begin{array}{l}\text { Serious fractures occur, anchorage function } \\
\text { fails }\end{array}$ & \\
\hline \multirow{3}{*}{ Drainage device } & \multirow{3}{*}{ Fracture } & 2 & Local fractures occur & \multirow{3}{*}{$\begin{array}{c}\text { Fractures } \leq 3, \text { damaged area } \leq 10 \% \\
\text { total area } \\
\begin{array}{c}3<\text { fractures } \leq 5,10 \%<\text { damaged area } \\
\leq 30 \% \text { total area } \\
\text { Fractures }>5, \text { damaged area }>30 \% \\
\text { total area }\end{array}\end{array}$} \\
\hline & & 3 & Multiple fractures occur & \\
\hline & & 4 & Serious fractures occur & \\
\hline
\end{tabular}

Table 6. Inspection index evaluation of the BECI of seamless type.

\begin{tabular}{|c|c|c|c|c|}
\hline Inspection Object & Inspection Index & Scale & Qualitative Description & Quantitative Description \\
\hline \multirow{3}{*}{$\begin{array}{c}\text { Elastic expansion } \\
\text { body }\end{array}$} & \multirow{3}{*}{ Fracture } & 2 & Local fractures occur & \multirow{3}{*}{$\begin{array}{c}\text { Damaged area } \leq 10 \% \text { total area } \\
10 \%<\text { damaged area } \leq 30 \% \text { total area } \\
\text { Damaged area }>30 \% \text { total area }\end{array}$} \\
\hline & & 3 & Multiple fractures occur & \\
\hline & & 4 & Serious fractures occur, anchorage function fails & \\
\hline \multirow{3}{*}{ Steel cover plate } & \multirow{3}{*}{ Abrasion } & 2 & Local abrasions occur & \multirow{3}{*}{$\begin{array}{c}\text { Abrasion area } \leq 10 \% \text { total area } \\
10 \%<\text { abrasion area } \leq 30 \% \text { total area } \\
\text { Abrasion area }>30 \% \text { total area }\end{array}$} \\
\hline & & 3 & Multiple abrasions occur & \\
\hline & & 4 & Massive abrasions occur & \\
\hline \multirow{3}{*}{ Nail } & \multirow{3}{*}{ Corrosion } & 2 & Local corrosions occur & Corrosions $\leq 3$ \\
\hline & & 3 & Multiple corrosions occur & $3<$ corrosions $\leq 5$ \\
\hline & & 4 & Massive corrosions occur & Corrosions $>\overline{5}$ \\
\hline \multirow{3}{*}{ Foam plate } & \multirow{3}{*}{ Fracture } & 2 & Local fractures occur & \multirow{3}{*}{$\begin{array}{c}\text { Damaged area } \leq 10 \% \text { total area } \\
10 \%<\text { damaged area } \leq 30 \% \text { total area } \\
\text { Damaged area }>30 \% \text { total area }\end{array}$} \\
\hline & & 3 & Multiple fractures occur & \\
\hline & & 4 & Serious fractures occur & \\
\hline
\end{tabular}

\subsubsection{Calculation of Progressive Assessment}

In accordance with the obtained technical condition scales of each inspection index of each member in on-site inspection process, numerical progressive assessment is carried out from bottom to top. Specifically, the numerical calculations of the technical condition indices of members, components, main structure and accessory structure, and the overall BECI will be conducted successively, where the necessity of replacement will be settled in consequence. 
1. Technical condition assessment of BECI members

The technical condition assessment of BECI members is calculated as follows:

$$
\begin{aligned}
& \mathrm{MMCI}_{i-l}\left(\mathrm{AMCI}_{i-l}\right)=100-\sum_{x=1}^{k} N_{x} \\
& N_{e}=\mathrm{DP}_{i-l-j}, e=1 \\
& N_{e}=\frac{\mathrm{DP}_{i-l-j}}{100 \times \sqrt{e}}\left(100-\sum_{r=1}^{e-1} N_{r}\right)(\text { where } j=e), e \geq 2
\end{aligned}
$$

where MMCI and AMCI are the condition indices of members, which belong to the main structure and accessory structure, respectively; $i, l$, and $j$ denote component $i$, member $l$, and inspection index $j ; k$ is the quantity of inspection indices; $x, e$, and $r$ are introduced variables; DP is the deduct point, which is determined by the technical condition scales of each inspection index according to Table 7.

2. Technical condition assessment of BECI components

The technical condition assessment of BECI components is calculated as follows:

$$
\begin{aligned}
& \mathrm{MCCI}_{i}=\overline{\mathrm{MMCI}}_{i}-\left(100-\mathrm{MMCI}_{i, \min }\right) / t \\
& \mathrm{ACCI}_{i}=\overline{\mathrm{AMCI}}_{i}-\left(100-\mathrm{AMCI}_{i, \min }\right) / t \\
& \mathrm{MCCI}_{i}\left(\mathrm{ACCI}_{i}\right)=0, \text { when } \mathrm{MCCI}_{i}\left(\mathrm{ACCI}_{i}\right)<0
\end{aligned}
$$

where MCCI and ACCI are the condition indices of components, which belong to the main structure and accessory structure, respectively; $i$ denotes component $i ; t$, as is illustrated in Table 8 , is the correction coefficient, which is a variable with the quantity of members and introduced to neutralize the adverse effect of individual members on overall component technical condition assessment.

3. Technical condition assessment of BECI main structure and accessory structure

The technical condition assessment of BECI main structure and accessory structure is calculated as follows:

$$
\operatorname{MSCI}(\mathrm{ASCI})=\sum_{i=1}^{c} \operatorname{MCCI}_{i}\left(\mathrm{ACCI}_{i}\right) \times \mathrm{W}_{i}
$$

where here MSCI and ASCI are the condition indices of main structure and accessory structure; $i$ denotes component $i ; c$ represents the quantity of components; as is shown in Table $9, W_{i}$ is the calculation weight of each component, which is established via an analytic hierarchy process method under the guidance of the transportation industry standard of the People's Republic of China [35,36].

4. Technical condition assessment of overall BECI

The technical condition assessment of overall BECI is calculated as follows:

$$
\mathrm{S}_{\mathrm{I}}=\mathrm{MSCI} \times \mathrm{W}_{M S}+\mathrm{ASCI} \times \mathrm{W}_{A S}
$$

where $S_{\text {I }}$ denotes the summative condition index of overall BECI; $\mathrm{W}_{M S}$ and $\mathrm{W}_{A S}$ are the calculation weights of the main structure and accessory structure, respectively, which are valued according to Table 10.

5. Technical condition scale classification of BECI

In accordance with the computation results of $S_{I}$, the technical condition scales $S_{S}$ of $\mathrm{BECI}$ are classified and corresponding maintenance suggestions are proposed, which is exhibited in Table 11.

6. Inspection control index of BECI

In particular, the technical condition scale of BECI will be classified as 4 without following up subsequent assessment process if the results of on-site inspection satisfy 
the inspection control indices, which implies that a BECI replacement is necessary to be developed immediately. The inspection control indices of BECI are proposed as follows:

- More than 2 fractures occur in side beam or intermediate beam;

- The damaged area of comb plate exceeds $30 \%$ and more than 3 defective units occur;

- The damaged area of elastic expansion body exceeds 30\%.

Compared with traditional inspection, this approach allows an exact number to be output when on-site inspectors find that the BECI is between two scales and it is difficult to completely make judgment, which proves the most significant improvement.

Table 7. Deduct point of inspection index.

\begin{tabular}{ccccc}
\hline \multirow{2}{*}{$\begin{array}{c}\text { The Highest Scale That Can Be Achieved by } \\
\text { Inspection Index }\end{array}$} & \multicolumn{4}{c}{ Scale of Inspection Index } \\
\cline { 2 - 5 } & $\mathbf{1}$ & $\mathbf{2}$ & $\mathbf{3}$ & $\mathbf{4}$ \\
\hline 4 & 0 & 25 & 50 & 100 \\
\hline
\end{tabular}

Table 8. Value of correction coefficient $t$.

\begin{tabular}{cccc}
\hline Quantity of Members & $\boldsymbol{t}$ & Quantity of Members & $\boldsymbol{t}$ \\
\hline 1 & $\infty$ & 11 & 7.9 \\
2 & 10 & 12 & 7.7 \\
3 & 9.7 & 13 & 7.5 \\
4 & 9.5 & 14 & 7.3 \\
5 & 9.2 & 15 & 7.2 \\
6 & 8.9 & 16 & 7.08 \\
7 & 8.7 & 17 & 6.96 \\
8 & 8.5 & 18 & 6.84 \\
9 & 8.3 & 19 & 6.72 \\
10 & 8.1 & 20 & 6.6 \\
\hline
\end{tabular}

Table 9. Calculation weight of the component.

\begin{tabular}{|c|c|c|c|c|}
\hline Installation & Part & No. & Component & $\mathbf{W}_{i}$ \\
\hline \multirow{3}{*}{$\begin{array}{c}\text { MA } \\
\text { Modular type }\end{array}$} & Main structure & 1 & Side beam & 0.75 \\
\hline & & 2 & Anchorage concrete & 0.25 \\
\hline & Accessory structure & 3 & Rubber sealing tape & 1 \\
\hline \multirow{7}{*}{$\begin{array}{c}\text { MB } \\
\text { Modular type }\end{array}$} & Main structure & 1 & Side beam & 0.27 \\
\hline & & 2 & Intermediate beam & 0.27 \\
\hline & & 3 & Bearing system & 0.10 \\
\hline & & 4 & Displacement control system & 0.10 \\
\hline & & 5 & Elastic support & 0.10 \\
\hline & & 6 & Anchorage concrete & 0.16 \\
\hline & Accessory structure & 7 & Rubber sealing tape & 1 \\
\hline \multirow{4}{*}{$\begin{array}{c}\text { SC } \\
\text { Comb plate type }\end{array}$} & Main structure & 1 & Comb plate & 0.52 \\
\hline & & 2 & Anchor bolt & 0.24 \\
\hline & & 3 & Anchorage concrete & 0.24 \\
\hline & Accessory structure & 4 & Drainage device & 1 \\
\hline \multirow{7}{*}{$\begin{array}{c}\text { SSA, SSB } \\
\text { Comb plate type }\end{array}$} & Main structure & 1 & Fixed comb plate & 0.25 \\
\hline & & 2 & Movable comb plate & 0.35 \\
\hline & & 3 & Stainless steel sliding plate & 0.05 \\
\hline & & 4 & Anchor bolt & 0.10 \\
\hline & & 5 & $\begin{array}{c}\text { Multidirectional displacement } \\
\text { device }\end{array}$ & 0.12 \\
\hline & & 6 & Anchorage concrete & 0.13 \\
\hline & Accessory structure & 7 & Drainage device & 1 \\
\hline \multirow{4}{*}{ Seamless type } & Main structure & 1 & Elastic expansion body & 1 \\
\hline & Accessory structure & 2 & Steel cover plate & 0.40 \\
\hline & & 3 & Nail & 0.40 \\
\hline & & 4 & Foam plate & 0.20 \\
\hline
\end{tabular}


Table 10. Weights of main structure and accessory structure.

\begin{tabular}{cc}
\hline Part & Weight \\
\hline Main structure & 0.8 \\
Accessory structure & 0.2 \\
\hline
\end{tabular}

Table 11. Technical condition scale classification.

\begin{tabular}{cccc}
\hline $\begin{array}{c}\text { Technical Condition } \\
\text { Scale } \text { S }_{\text {S }}\end{array}$ & $\begin{array}{c}\text { Technical Condition } \\
\text { Index } \text { S }_{\mathbf{I}}\end{array}$ & $\begin{array}{c}\text { Qualitative } \\
\text { Description }\end{array}$ & $\begin{array}{c}\text { Maintenance } \\
\text { Suggestion }\end{array}$ \\
\hline 1 & {$[90,100]$} & Healthy & Normal maintenance \\
\hline 2 & {$[75,90)$} & Slightly damaged & $\begin{array}{c}\text { Individual members } \\
\text { repair or replacement }\end{array}$ \\
\hline 3 & {$[60,75)$} & Obviously damaged & $\begin{array}{c}\text { Essential components } \\
\text { replacement }\end{array}$ \\
\hline 4 & {$[0,60)$} & Seriously damaged & BECI replacement \\
\hline
\end{tabular}

\subsubsection{Software Development}

Derived from the composition design, the "Bridge Expansion and Contraction Installation Assessment (BECIA)" software was developed based on the MATLAB platform to assist decision makers in making replacement decision efficiently. The software provides decision makers with a friendly user interface (Figure 3) where the users are only required to input the inspection index scales succinctly, and the technical condition index and scale of overall BECI will be output through automatic computation. Compared with traditional assessment, the development of software implies that both project managers and on-site inspector are entitled to participate in decision making directly, which proves the most significant improvement.

Type Selection

MA modular type

Component

Main Structure

Side Beam

Anchorage Concrete

\section{Accessory Structure}

Rubber Sealing Tape
Member Inspection Index Evenness Spacing

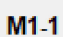

M1-2
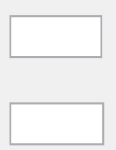

M2-1

M2-2

Fracture

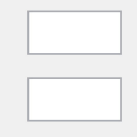

A3-1

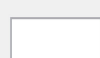

Aging

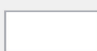

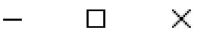
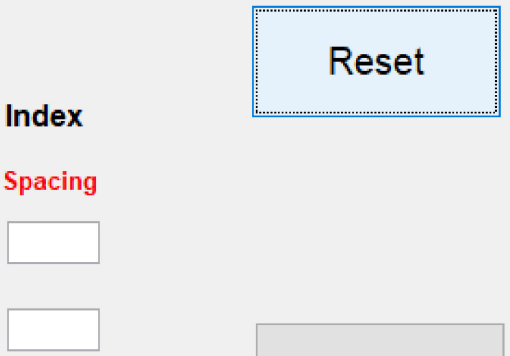

Start

Result

Techinical Index

Figure 3. User interface of BECIA software. 


\subsection{Selection of Replacement Plan Using Hybrid Chaotic Whale Optimization Algorithm}

The above-mentioned BECI technical condition assessment approach proves capable of being utilized to determine the necessity of replacement. Specifically, if the technical condition scale of overall BECI is defined as 4 or the inspection control index is satisfied, BECI replacement will be carried out and the analytic hierarchy process method will be employed to select the performance-based optimal replacement plan. In particular, the hybrid chaotic whale optimization algorithm is introduced originally to modify and automate the standard AHP.

\subsubsection{Analytic Hierarchy Process}

Under the suggestions of experts selected from relevant research field via the Delphi method [37], the hierarchy structure model of performance-based optimal replacement plan selection is constructed and illustrated in Figure 4, which takes 12 kinds of design, construction, and management requirements into consideration.

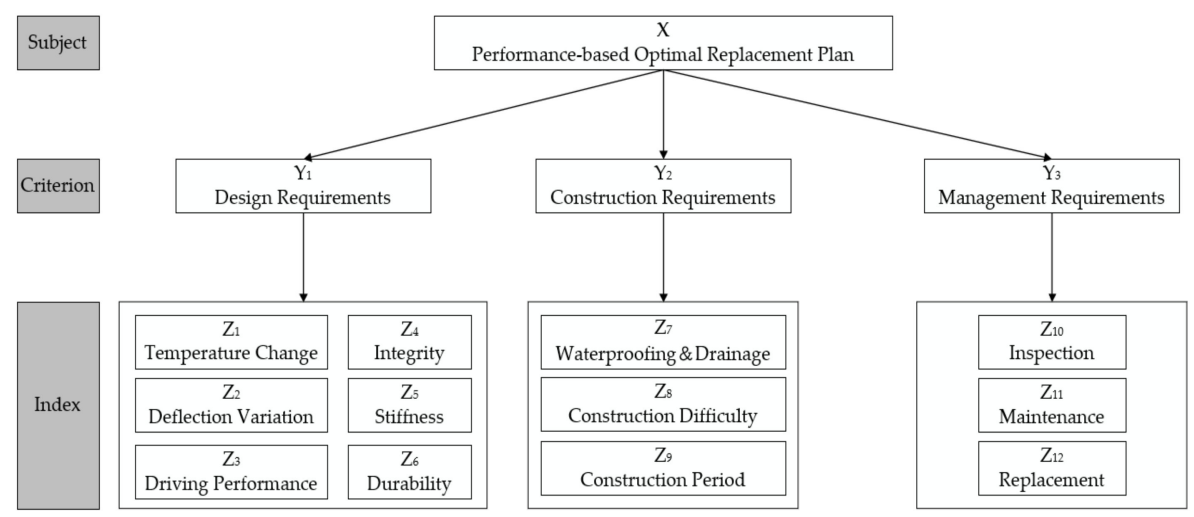

Figure 4. Hierarchy structure model of the performance-based replacement method selection.

In accordance with the 1-9 evaluation scale method [38], pairwise comparison matrices will be determined via the Delphi method. To put it in practical terms, the comparison matrix $X$ is exhibited as an example:

$$
X=\left(x_{i j}\right)_{3 \times 3}=\left(\begin{array}{ccc}
1 & Y_{1} / Y_{2} & Y_{1} / Y_{3} \\
Y_{2} / Y_{1} & 1 & Y_{2} / Y_{3} \\
Y_{3} / Y_{1} & Y_{3} / Y_{2} & 1
\end{array}\right)
$$

where $Y_{1} / Y_{2}$ is the relative priority of criterion $Y_{1}$ with respect to criterion $Y_{2}$, whose specific value is determined by the results of the above-mentioned 1-9 evaluation scale method, and the specific evaluation regulations are demonstrated in Table 12.

Table 12. Evaluation scale classification.

\begin{tabular}{cc}
\hline Evaluation Scale & Comparison of the Priority \\
\hline 1 & $Y_{1}$ and $Y_{2}$ are equally important \\
3 & $Y_{1}$ is slightly important compared with $Y_{2}$ \\
5 & $Y_{1}$ is obviously important compared with $Y_{2}$ \\
7 & $Y_{1}$ is highly important compared with $Y_{2}$ \\
9 & $Y_{1}$ is extremely important compared with $Y_{2}$ \\
$2,4,6,8$ & Intermediate values used to represent compromise \\
\hline
\end{tabular}

After the construction of comparison matrices, the asymptotic normalization coefficient method is utilized to realize the process of level simple sequence (LLS), where the eigenvector of comparison matrix $w_{i}$ is defined as the hierarchical weight vector and calculated as follows [3]: 


$$
M_{i}=\prod_{j=1}^{n} x_{i j}, \overline{w_{i}}=\sqrt[n]{M_{i}}, \quad w_{i}=\frac{\overline{w_{i}}}{\sum_{j=1}^{n} \overline{w_{j}}}(i=1,2 \ldots n)
$$

where $M_{i}$ is the chain-multiplication result of $x_{i j}$, and $n$ is the order of comparison matrix.

Simultaneously, the related maximum eigenvalue is $\lambda_{\max }=\sum_{i=1}^{n} \frac{(X w)_{i}}{n w_{i}}$, where $(X w)_{i}$ is the part $i$ of $X w$.

In accordance with obtained $\lambda_{\max }$, the consistency ratio (CR) and consistency index (CI) are introduced to perform a consistency test, which demonstrates the rationality of the constructed comparison matrix and can be calculated as follows:

$$
\begin{aligned}
& C R=\frac{C I}{R I} \\
& C I=\frac{\lambda_{\max }-n}{n-1}
\end{aligned}
$$

where $R I$ is the random consistency index that corresponds to the order of comparison matrix and can be defined as Table 13 illustrates.

Table 13. Random consistency index.

\begin{tabular}{ccccccccc}
\hline $\mathbf{N}$ & $\mathbf{1}$ & $\mathbf{2}$ & $\mathbf{3}$ & $\mathbf{4}$ & $\mathbf{5}$ & $\mathbf{6}$ & $\mathbf{7}$ & $\mathbf{8}$ \\
\hline$R I$ & 0.00 & 0.00 & 0.58 & 0.90 & 1.12 & 1.24 & 1.32 & 1.41 \\
\hline
\end{tabular}

If $C R<0.10$, the matrix consistency is acceptable. Otherwise, the matrix is inconsistent and is required to be modified. In particular, the matrix is defined as the complete consistency matrix when $C R$ is equal to 0 .

\subsubsection{Modification Strategy of Inconsistent Comparison Matrix}

In terms of high-order matrices that were initiated under the circumstance of human factors, it is difficult to fulfil the requirements of consistency test, thus motivating the modification of inconsistent comparison matrix. In consideration of both the characteristics of the matrix with complete consistency and the relationship between the initiated matrix and the induced matrix, the mathematical model is established through the least square method, which leads to a multi-objective optimization problem.

$M=\left(m_{i j}\right)_{n \times n}$ and $X=\left(x_{i j}\right)_{n \times n}$ are introduced as the initiated matrix and the induced matrix, respectively. If $X$ is supposed to be a complete consistency matrix, Equation (8) will be established as follows [9]:

$$
x_{i j}=w_{i} / w_{j}
$$

Hence, the first least square mathematical model is proposed as follows, which aims to improve the consistency:

$$
\begin{array}{cl} 
& \min \sum_{i=1}^{n} \sum_{j=1}^{n}\left(x_{i j}-w_{i} / w_{j}\right)^{2} \\
\text { s.t. } & \sum_{i=1}^{n} w_{i}=1, w_{i}>0, \\
& x_{i j}=1 / x_{i j}, \\
& i, j=1,2,3 \ldots n .
\end{array}
$$

However, not only does the consistency of comparison matrix need to be enhanced, but also the suggestions of experts should be respected. Therefore, the second least square mathematical model is constructed as follows, which aims to reserve the original information of initiated matrix: 


$$
\begin{array}{ll} 
& \min \sum_{i=1}^{n} \sum_{j=1}^{n}\left(x_{i j}-m_{i j}\right)^{2} \\
\text { s.t. } & x_{i j} \in\left[(1-\mu) m_{i j},(1+\mu) m_{i j}\right], \\
& 0<\mu<1, \\
& i, j=1,2,3 \ldots . .
\end{array}
$$

Eventually, as Equation (11) illustrates, the above-mentioned mathematical models are integrated through weighted method, which turns the modification of inconsistent comparison matrix into a single-objective optimization problem with $n(n+1) / 2$ variables due to the symmetry of comparison matrix.

$$
\begin{array}{ll}
\min L=\sum_{i=1}^{n} \sum_{j=1}^{n}\left[k_{1}\left(x_{i j}-m_{i j}\right)^{2}+k_{2}\left(x_{i j}-w_{i} / w_{j}\right)^{2}\right] \\
\text { s.t. } \quad \sum_{i=1}^{n} w_{i}=1, w_{i}>0, \\
\quad k_{1}+k_{2}=1, k_{1}, k_{2}>0 \\
\quad x_{i j}=1 / x_{i j}, \\
\quad x_{i j} \in\left[(1-\mu) m_{i j},(1+\mu) m_{i j}\right], 0<\mu<1, \\
\quad i, j=1,2,3 \ldots n .
\end{array}
$$

\subsubsection{Hybrid Chaotic Whale Optimization Algorithm}

In accordance with the established mathematical model, the hybrid chaotic whale optimization algorithm is introduced to solve the objective function $\min L$, where both the modified comparison matrix and hierarchical weights will be output automatically.

1. Standard whale optimization algorithm.

Derived from the bubble-net hunting behavior of humpback whales (Figure 5), the standard whale optimization algorithm was proposed as a meta-heuristic algorithm to handle optimization problems in 2016, which contains 3 principal operations as follows:

- Encircling prey.

The humpback whales are capable of recognizing the location of prey, which indicates the solution space in WOA, and encircle it. Additionally, the current best candidate solution is assumed to be the target prey or close to the optimum, which motivates other search agents to update their positions towards the best one. This behavior is simulated by Equation (12) as follows:

$$
\begin{aligned}
& \vec{D}=\left|\vec{C} \cdot \overrightarrow{X^{*}}(t)-\vec{X}(t)\right| \\
& \vec{X}(t+1)=\overrightarrow{X^{*}}(t)-\vec{A} \cdot \vec{D}
\end{aligned}
$$

where $t$ denotes the current iteration, and $\vec{D}$ and $\vec{X}$ are position vectors. In particular, $\vec{X}^{*}$ is the position vector of the best solution acquired so far which should be updated in each iteration if a better solution occurs. $\vec{A}$ and $\vec{C}$ are the coefficient vectors, which can be calculated as follows:

$$
\begin{aligned}
& \vec{A}=2 \vec{a} \cdot \vec{r}-\vec{a} \\
& \vec{C}=2 \cdot \vec{r}
\end{aligned}
$$

where $\vec{a}$ is decreased from 2 to 0 linearly over the course of iterations in both exploration and exploitation phases, and $\vec{r}$ is a random vector in $[0,1]$.

- Bubble-net attacking (exploitation phase).

In order to model the bubble-net attacking behavior of humpback whales mathematically, the shrinking encircling mechanism and spiral updating position strategy are 
introduced, where the mechanism is realized by setting random values for $\vec{A}$ in $[-1,1]$, and the spiral updating position strategy is described, as Equation (15) demonstrates:

$$
\begin{aligned}
& \vec{X}(t+1)=\overrightarrow{D^{\prime}} \cdot e^{b l} \cdot \cos (2 \pi l)+\overrightarrow{X^{*}}(t) \\
& \overrightarrow{D^{\prime}}=\left|\overrightarrow{X^{*}}(t)-\vec{X}(t)\right|
\end{aligned}
$$

where $\overrightarrow{D^{\prime}}$ indicates the distance of the whale to the prey, and $b$ is a constant for defining the logarithmic spiral shapes, random number $l \in[-1,1]$.

It is assumed that there is a probability of $50 \%$ to switch between either the encircling prey mode or the spiral model to update the position of whales, which can be mathematically expressed as follows:

$$
\begin{array}{ll}
\vec{X}(t+1)=\overrightarrow{X^{*}}(t)-\vec{A} \cdot \vec{D} & \text { ifp }<0.5 \\
\vec{X}(t+1)=\overrightarrow{D^{\prime}} \cdot e^{b l} \cdot \cos (2 \pi l)+X^{*}(t) & \text { ifp } \geq 0.5
\end{array}
$$

where random number $p \in[0,1]$.

- $\quad$ Search for prey (exploration phase).

The humpback whales search randomly according to the position of each other, which is simulated through the similar approach based on the variation of $\vec{A}$. The exploration phase and the exploitation phase differ in that the position of search agent is updated by a randomly chosen search agent rather than by the best search agent at present. To put it in practical terms, the whales will swim randomly outside the shrinking encircling area when $|\vec{A}|>1$, which emphasizes the global search of WOA and can be described as follows:

$$
\begin{aligned}
& \vec{D}=\left|\vec{C} \cdot \vec{X}_{\text {rand }}(t)-\vec{X}(t)\right| \\
& \vec{X}(t+1)=\vec{X}_{\text {rand }}(t)-\vec{A} \cdot \vec{D}
\end{aligned}
$$

where $\vec{X}_{\text {rand }}(t)$ is a random position vector of a search agent chosen from the current population.

2. Tent chaotic mapping strategy.

The random-based optimization algorithm using chaotic variables instead of random variables are defined as the chaotic optimization algorithm, which is capable of carrying out global searches at both higher speed and accuracy than stochastic searches that depend on probabilities due to the non-repetition and ergodicity of chaos. Additionally, compared with other chaotic maps, Tent chaotic map proves efficient to enhance the performance of standard WOA when the process of population initialization is conducted. Hence, the Tent chaotic mapping strategy is introduced and expressed as follows [39]:

$$
x_{k+1, d}= \begin{cases}\frac{x_{k d}}{0.7} & x_{k d}<0.7 \\ \frac{10}{3}\left(1-x_{k d}\right) & x_{k d} \geq 0.7\end{cases}
$$

where $k$ denotes the search agent $k, d$ indicates the dimension $d$ and $x_{k d} \in[0,1]$.

Specifically, a random vector is generated as the position vector of the first search agent in the solution space of optimization problem. Then, other position vectors of the rest search agents are calculated by Equation (17), where the chaotic set is formed. Ultimately, the obtained position vectors are mapped to the solution space, which can be realized by Equation (18).

$$
y_{k d}=l b_{d}+x_{k d} \cdot\left(u b_{d}-l b_{d}\right)
$$


where $l b_{d}$ and $u b_{d}$ are the lower boundary and upper boundary of the optimization problem, and $y$ indicates the mapped position of the search agent.

3. Lévy flight strategy.

Confronted with high-dimensional and multi-modal optimization problems, the performance of standard WOA remains insufficient due to the dependence on randomness, which results in the risk of local optimum. Originally, the Lévy flight strategy was introduced to develop the cuckoo search (CS) algorithm, which proves efficient with both the high speed and accuracy of global convergence. Therefore, in order to prevent the optimization algorithm from trapping in the local optimum and enhance the global search performance, the Lévy flight strategy is conducted to be hybridized with the chaotic WOA, which is utilized to update the position of whales again at the later stage of each iteration and can be demonstrated as follows [40]:

$$
\vec{X}(t+1)=\vec{X}_{\text {rand }}(t)-\alpha \cdot \operatorname{sign}[\text { rand }-1 / 2] \oplus \operatorname{Lévy}(s)
$$

where sign [rand $-1 / 2]$ takes only 3 values: $-1,0$, or 1 , the product $\oplus$ denotes the entry wise multiplication, and $\alpha$ is the step size related to the scales of optimization problems, which can be described as follows:

$$
\alpha=0.01\left[\vec{X}_{\text {rand }}(t)-\vec{X}(t)\right]
$$

The Lévy flight strategy proves a non-Gaussian random process, where the step lengths follow the Lévy distribution and can be expressed as follows:

$$
\operatorname{Lévy(s)} \sim|s|^{-1-\beta}, 0<\beta \leq 2
$$

where $\beta$ is an index, $s$ indicates the random step length of Lévy flight, which can be obtained by Mantegna's algorithm [41]:

$$
s=\frac{\mu}{|v|^{1 / \beta}}
$$

where $\beta$ is set to be $1.5, \mu$ and $v$ obey the normal distribution and can be acquired as follows:

$$
\begin{gathered}
\mu \sim N\left(0, \sigma_{\mu}^{2}\right), v \sim N\left(0, \sigma_{v}^{2}\right) \\
\sigma_{\mu}=\left\{\frac{\Gamma(1+\beta) \cdot \sin (\pi \beta / 2)}{\Gamma[(1+\beta) / 2] \beta \cdot 2^{(\beta-1) / 2}}\right\}^{1 / \beta}, \sigma_{v}=1
\end{gathered}
$$

where $\Gamma$ is the standard Gamma function.

In summary, the optimization flowchart of the hybrid chaotic whale optimization algorithm is established in the light of above theories, which is exhibited in Figure 6. Additionally, both the modified comparison matrix and hierarchical weights will be output automatically when the optimal solution of objective function $\min L$ is satisfied or the max iteration is achieved. 


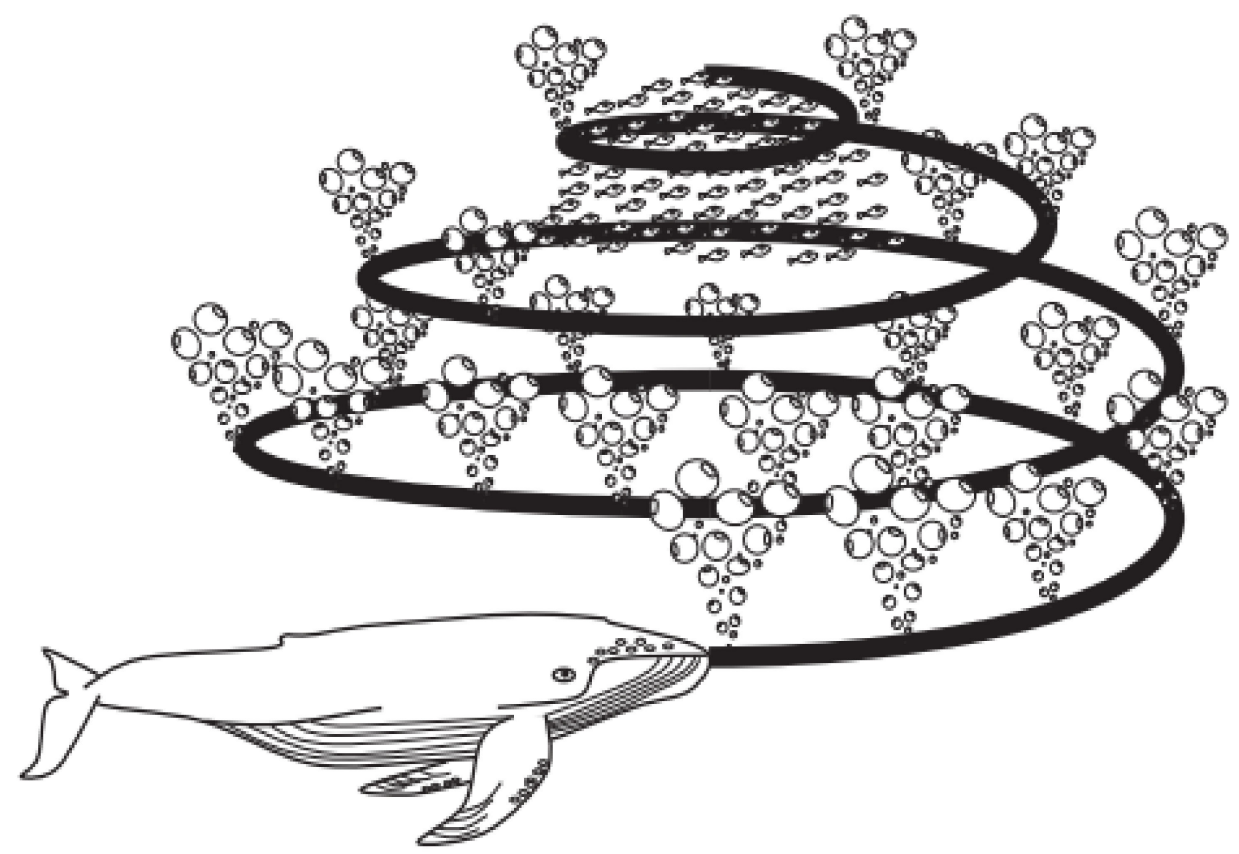

Figure 5. Bubble-net hunting behavior of humpback whales.

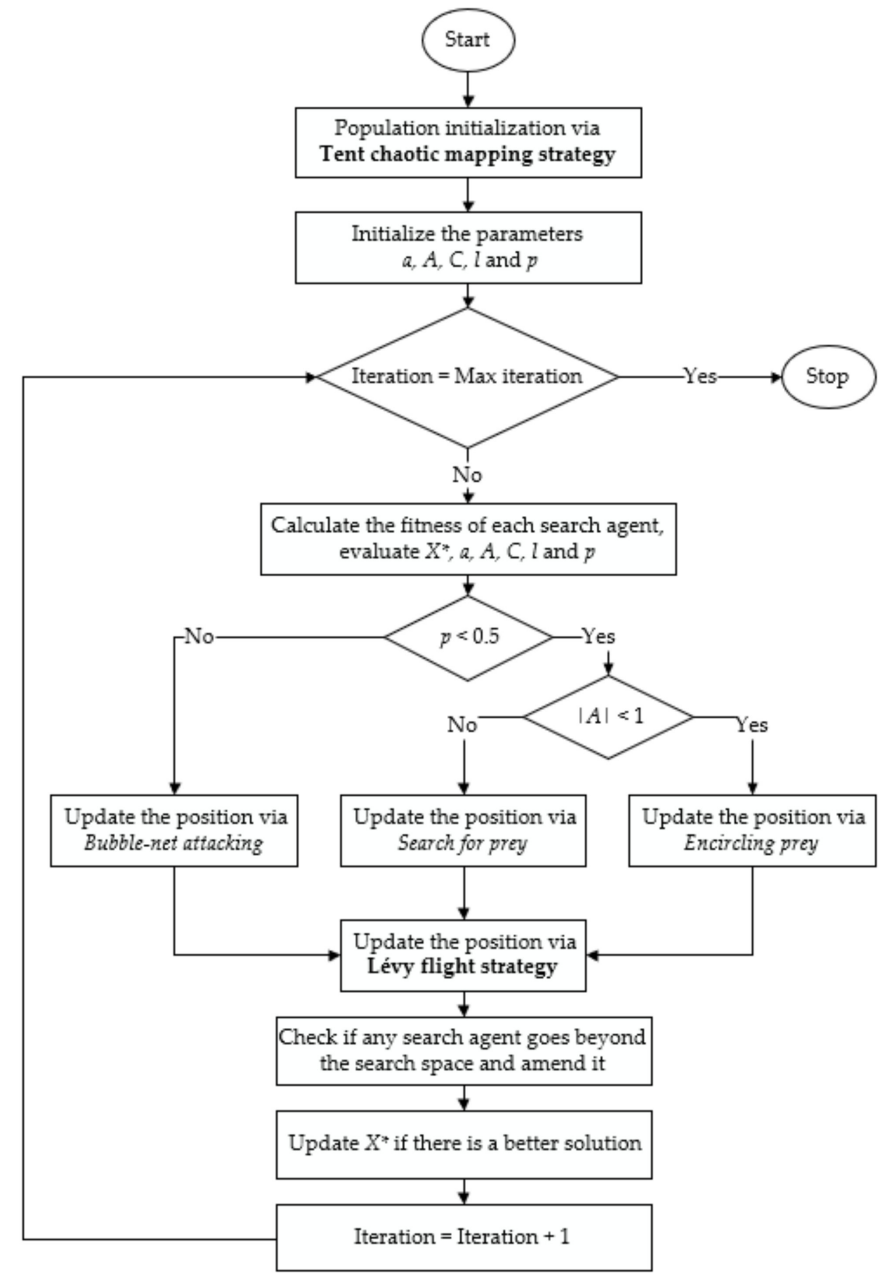

Figure 6. Optimization flowchart of hybrid chaotic whale optimization algorithm. 


\subsubsection{Performance Coefficient Determination}

In accordance with the obtained hierarchical weights, a mathematical model is established to determine the performance coefficient of each replacement plan, where the performance-based optimal replacement plan with the highest performance coefficient will be selected as follows:

$$
P=\left(Y_{1} \cdot \sum_{i=1}^{6} Z_{i} \cdot I_{i}+Y_{2} \cdot \sum_{i=7}^{9} Z_{i} \cdot I_{i}+Y_{3} \cdot \sum_{i=10}^{12} Z_{i} \cdot I_{i}\right) / 100
$$

where $P$ denotes the performance coefficient of the replacement plan, $Y$ and $Z$ are the hierarchical weights of criteria and indices in AHP, $i$ represents index $i$, and $I$ indicates the performance coefficients of the indices, which are obtained under the suggestion of experts via the Delphi method and range from 1 to 100.

\section{Case Study}

\subsection{Research Background}

In this article, the BECI O and $\mathrm{M}$ project of Guo Bridge is introduced as a case study, which is located in Taihe County, Fuyang City, Anhui Province, China and belongs to the provincial highway S254.

Guo bridge is in service with a total length of $20.6 \mathrm{~m}$ and a width of $8.6 \mathrm{~m}$, where the MA modular type BECI is applied with an expansion amount of $60 \mathrm{~mm}$. Under the circumstances of heavy-load vehicles and long-term environmental impact, the performance of BECI in Guo Bridge has become unfavorable, thus motivating the technical condition assessment process. In October 2018, an on-site inspection was conducted on Guo bridge, where the image data were acquired and demonstrated in Figure 7.

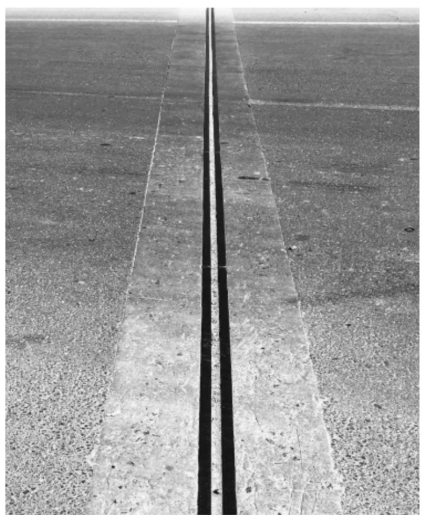

(a) Overview of BECI

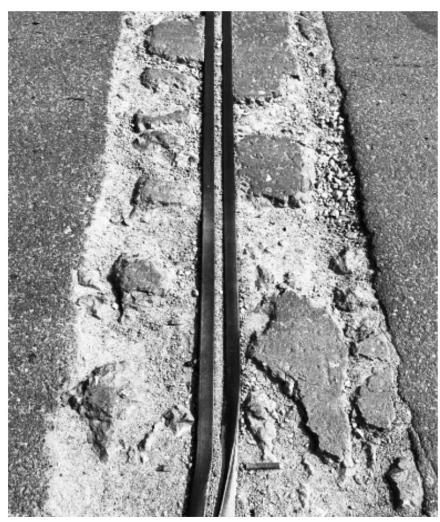

(c) Fracture in anchorage concrete

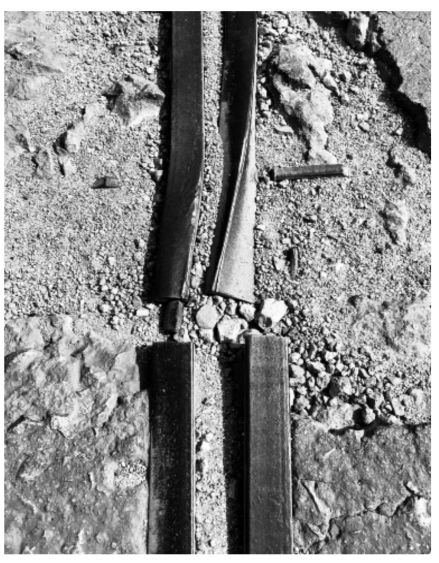

(b) Elevation difference in side beam

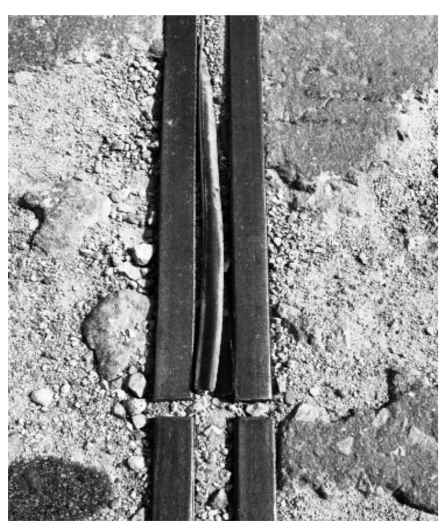

(d) Aging of rubber sealing tape

Figure 7. BECI of Guo Bridge. 


\subsection{Technical Condition Assessment}

Above all, the BECI of Guo Bridge is hierarchically classified into three layers and numbered in accordance with Table 1 . In addition, combined with the results of on-site inspection and the regulations proposed in Table 2, the inspection index evaluation can be carried out.

\subsubsection{Inspection Index Evaluation}

The elevation differences of $25 \mathrm{~mm}$ occur in both the left and right side beams, where the index evaluation scales can be defined as 3; the spacing of $51 \mathrm{~mm}$ between side beams proves slightly narrow, which is more than $50 \mathrm{~mm}$ but less than the design value $(60 \mathrm{~mm})$ and indicates the inspection index evaluation scale is 2 . Referring to Table 7 , the deduct points can be obtained:

$$
\mathrm{DP}_{1-1-1}=\mathrm{DP}_{1-2-1}=50, \mathrm{DP}_{1-1-2}=\mathrm{DP}_{1-2-2}=25
$$

More than five serious fractures occurred in both the left and right anchorage concrete areas, and the damaged areas both exceed $20 \%$ of total area, where the index evaluation scales should be determined as 4 . Referring to Table 7 , the deduct points are exhibited as follows:

$$
\mathrm{DP}_{2-1-1}=\mathrm{DP}_{2-2-1}=100
$$

There are three fractures that occurred in the rubber sealing tape, where the damaged area exceeds $20 \%$ of total area but less than $50 \%$. The inspection index evaluation scale of aging should be defined as 3 . Similarly, the deduct point is acquired:

$$
\mathrm{DP}_{3-1-1}=50
$$

\subsubsection{Calculation of Progressive Assessment}

The calculation of progressive assessment can be performed according to the deduct points gained above.

1. Technical condition assessment of BECI members.

- Members of side beam.

According to Equation (1), the technical condition indices (keep two decimal place) of the left and right side beam are calculated as follows:

$$
\begin{aligned}
& N_{1}=\mathrm{DP}_{1-1-1}=50 \\
& N_{2}=\frac{\mathrm{DP}_{1-1-2}}{100 \times \sqrt{e}}\left(100-\sum_{\mathrm{r}=1}^{\mathrm{e}-1} N_{\mathrm{r}}\right)=\frac{25}{100 \times \sqrt{2}}\left(100-\sum_{r=1}^{1} N_{1}\right)=8.84 \\
& \mathrm{MMCI}_{1-1}=100-\sum_{e=1}^{2} N_{e}=100-(50+8.84)=41.16 \\
& \mathrm{MMCI}_{1-2}=\mathrm{MMCI}_{1-1}=41.16
\end{aligned}
$$

- Members of anchorage concrete.

In the same way, the technical condition indices of the left and right anchorage concrete are obtained:

$$
\begin{aligned}
& N_{1}=\mathrm{DP}_{2-1-1}=\mathrm{DP}_{2-2-1}=100 \\
& \mathrm{MMCI}_{2-1}=\mathrm{MMCI}_{2-2}=100-\sum_{e=1}^{1} N_{e}=100-(100)=0
\end{aligned}
$$

- Members of rubber sealing tape.

There is only one member of rubber sealing tape in MA modular type BECI. Therefore, the technical condition index is calculated as follows: 


$$
\begin{aligned}
& N_{1}=\mathrm{DP}_{3-1-1}=50 \\
& \mathrm{AMCI}_{3-1}=100-\sum_{e=1}^{1} N_{e}=100-(50)=50
\end{aligned}
$$

2. Technical condition assessment of BECI components.

- Side beam.

According to Table 8, the quantity of members of the side beam is two, which indicates the correction coefficient $t$ is defined as 10. Under the guidance of Equation (2), the technical condition index of side beam can be calculated:

$$
\begin{aligned}
& \overline{\mathrm{MMCI}}_{1}=\left(\mathrm{MMCI}_{1-1}+\mathrm{MMCI}_{1-2}\right) / 2=41.16 \\
& \mathrm{MCCI}_{1}=\overline{\mathrm{MMCI}}_{1}-\left(100-\mathrm{MMCI}_{1, \min }\right) / t=41.16-(100-41.16) / 10=35.28
\end{aligned}
$$

- Anchorage concrete.

In the same way, the technical condition index of anchorage concrete is acquired:

$$
\begin{aligned}
& \overline{\mathrm{MMCI}}_{2}=\left(\mathrm{MMCI}_{2-1}+\mathrm{MMCI}_{2-2}\right) / 2=0 \\
& \mathrm{MCCI}_{2}=\overline{\mathrm{MMCI}}_{2}-\left(100-\mathrm{MMCI}_{2, \min }\right) / t=0-(100-0) / 10=-10<0 \\
& \mathrm{MCCI}_{2}=0
\end{aligned}
$$

- Rubber sealing tape.

Next comes the technical condition index of anchorage concrete:

$$
\begin{aligned}
& \overline{\mathrm{AMCI}}_{3}=\mathrm{AMCI}_{3} / 1=50 \\
& \mathrm{ACCI}_{3}=\overline{\mathrm{AMCI}}_{3}-\left(100-\mathrm{AMCI}_{3, \text { min }}\right) / t=50-(100-50) / \infty=50
\end{aligned}
$$

3. Technical condition assessment of BECI main structure and accessory structure.

In accordance with Table 9, the calculation weights of side beam, anchorage concrete, and rubber sealing tape are gained, which are $0.75,0.25$, and 1 , respectively. The technical condition indices of the main structure and accessory structure are calculated by Equation (3) as follows:

$$
\begin{aligned}
& \mathrm{MSCI}=\sum_{i=1}^{c} \mathrm{MCCI}_{i} \times \mathrm{W}_{i}=35.28 \times 0.75+0 \times 0.25=26.46 \\
& \mathrm{ASCI}=\sum_{i=1}^{c} \mathrm{ACCI}_{i} \times \mathrm{W}_{i}=50 \times 1=50
\end{aligned}
$$

4. Technical condition assessment of overall BECI.

Referring to Table 10 and the technical indices gained above, the technical condition index of overall BECI is acquired by Equation (4):

$$
\mathrm{S}_{\mathrm{I}}=\mathrm{SMCI} \times \mathrm{W}_{M S}+\mathrm{SACI} \times \mathrm{W}_{A S}=26.46 \times 0.8+50 \times 0.2=31.17
$$

\subsubsection{Operation of BECIA Software}

Simultaneously, the BECIA software is conducted on technical condition assessment of the BECI of Guo Bridge, where only the inspection index scales are required to be input, and the technical condition index and scale of overall BECI will be acquired automatically, as Figure 8 illustrates. 


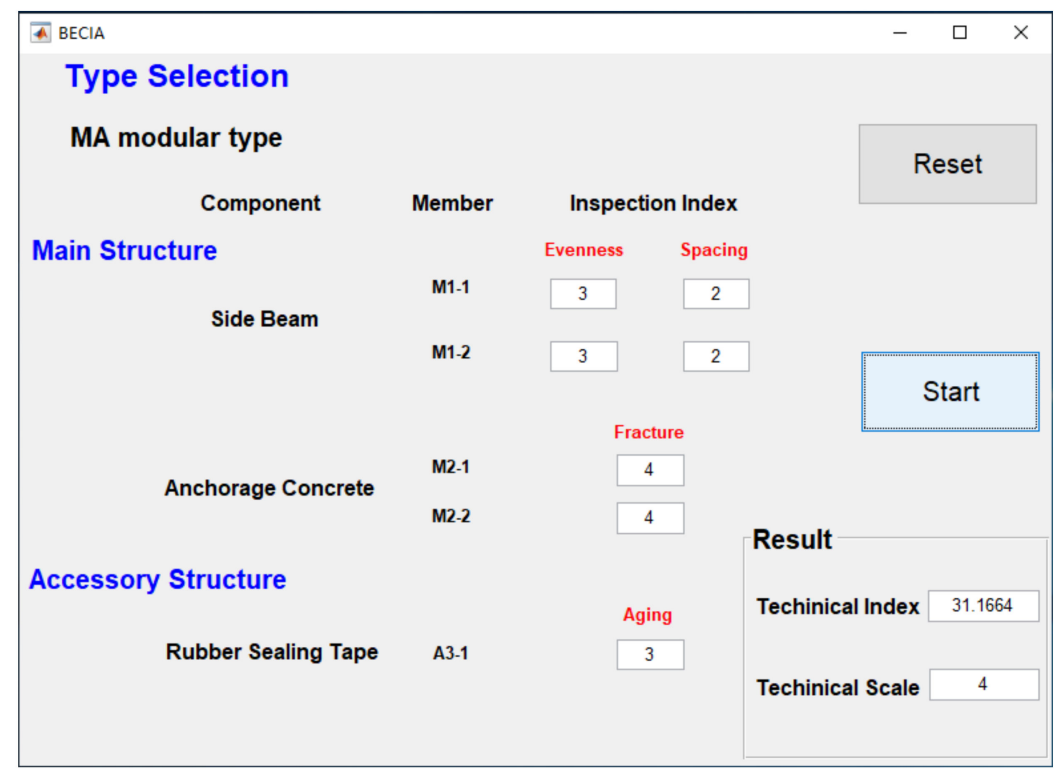

Figure 8. Operation interface of BECIA software.

Consequently, the results gained through BECIA are completely consistent with that of traditional manual calculation, which indicates that on-site inspectors are capable of participating in decision making independently via BECIA.

In conclusion, the technical condition scale of overall BECI of Guo Bridge is defined as 4 according to Table 11, which implies that the BECI are seriously damaged, and the replacement should be carried out immediately, thus leading to the selection of a replacement plan.

\subsection{Selection of Replacement Plan}

To begin with, in order to provide scientific guidance on the replacement plan selection, 16 experts selected from the expert database of Anhui Provincial Highway Institute were invited anonymously to solicit their opinions on research issues and phenomena via the Delphi method, where the candidate replacement plans are proposed in consideration of the allowable expansion amount of original BECI $(60 \mathrm{~mm})$ and the transportation industry standard of the People's Republic of China [1].

- Plan A: MA modular type with the allowable expansion amount from $20 \mathrm{~mm}$ to $80 \mathrm{~mm}$.

- Plan B: SC comb plate type with the allowable expansion amount from $60 \mathrm{~mm}$ to $240 \mathrm{~mm}$.

\subsubsection{Construction of Comparison Matrix}

Under the suggestions of the expert group, the priority of each index, criterion, and subject of AHP hierarchical model was distinguished through the 1-9 evaluation scale method, and the comparison matrices are constructed as follows:

$$
X=\left(\begin{array}{ccc}
1 & 1 & 2 \\
1 & 1 & 2 \\
1 / 2 & 1 / 2 & 1
\end{array}\right), Y_{1}=\left(\begin{array}{cccccc}
1 & 6 & 6 & 4 & 4 & 3 \\
1 / 6 & 1 & 1 & 1 / 5 & 1 / 5 & 1 / 3 \\
1 / 6 & 1 & 1 & 1 / 5 & 1 / 5 & 1 / 3 \\
1 / 4 & 5 & 5 & 1 & 1 & 1 / 4 \\
1 / 4 & 5 & 5 & 1 & 1 & 1 / 4 \\
1 / 3 & 3 & 3 & 4 & 4 & 1
\end{array}\right), Y_{2}=\left(\begin{array}{ccc}
1 & 1 / 3 & 2 \\
3 & 1 & 4 \\
1 / 2 & 1 / 4 & 1
\end{array}\right), Y_{3}=\left(\begin{array}{ccc}
1 & 1 / 2 & 1 \\
2 & 1 & 2 \\
1 & 1 / 2 & 1
\end{array}\right)
$$


In accordance with Equation (6), the eigenvectors and maximum eigenvalues of comparison matrices are obtained:

$$
\begin{array}{ll}
w_{X}=(0.40,0.40,0.20)^{T} & \lambda_{\max X}=3.15 \\
w_{Y_{1}}=(0.42,0.04,0.04,0.13,0.13,0.24)^{T} & \lambda_{\max Y_{1}}=6.66 \\
w_{Y_{2}}=(0.24,0.63,0.14)^{T} & \lambda_{\max Y_{2}}=3.06 \\
w_{Y_{3}}=(0.25,0.50,0.25)^{T} & \lambda_{\max Y_{3}}=3.00
\end{array}
$$

Next comes the result of the consistency test:

$$
\begin{array}{lll}
C I_{X}=0 R & I_{X}=0.58 & C R_{X}=0<0.10 \\
C I_{Y_{1}}=0.13 & R I_{Y_{1}}=1.24 & C R_{Y_{1}}=0.11>0.10 \\
C I_{Y_{2}}=0.03 & R I_{Y_{2}}=0.58 & C R_{Y_{2}}=0.05<0.10 \\
C I_{Y_{3}}=0 & R I_{Y_{3}}=0.58 & C R_{Y_{3}}=0<0.10
\end{array}
$$

Unfortunately, as a high-order matrix, $Y_{1}$ proves incapable of meeting the requirements of consistency test, which indicates that the acquired hierarchical weight $w_{Y_{1}}$ is not acceptable and modification should be performed via the hybrid chaotic whale optimization algorithm.

\subsubsection{Modification of Inconsistent Comparison Matrix}

In the light of above-mentioned strategies, the modification of inconsistent comparison matrix $Y_{1}$ is initiated. In order to achieve better consistency on the premise of reserving initial information, the parameters in Equation (11) are defined as follows, where the 15 elements in the upper right half above the trace of matrix and six hierarchical weights are integrated to turn the modification into a 21-dimentional optimization problem.

$$
\begin{array}{ll}
\min L=\sum_{i=1}^{n} \sum_{j=1}^{n}\left[0.3\left(x_{i j}-y_{1, i j}\right)^{2}+0.7\left(x_{i j}-w_{i} / w_{j}\right)^{2}\right] \\
\text { s.t. } \sum_{i=1}^{n} w_{i}=1, w_{i}>0 \\
\quad x_{i j}=1 / x_{i j} \\
\quad x_{i j} \in\left[0.7 y_{1, i j}, 1.3 y_{1, i j}\right] \\
\quad i, j=1,2,3 \ldots .
\end{array}
$$

Simultaneously, the proposed hybrid chaotic whale optimization algorithm is conducted to handle this optimization problem with MATLAB R2016a, where the modified comparison matrix and corresponding hierarchical weights are output automatically. It is worth mentioning that the function value gained after 1000 iterations will be output as the optimal fitness value due to its uncertainty in advance. Additionally, the modified comparison matrix is exhibited as follows:

$$
\begin{gathered}
Y_{1}=\left(\begin{array}{cccccc}
1 & 6.1514 & 6.1457 & 3.8134 & 3.9181 & 2.7247 \\
0.1626 & 1 & 0.9832 & 0.2600 & 0.2600 & 0.3507 \\
0.1627 & 1.0170 & 1 & 0.2600 & 0.2600 & 0.4333 \\
0.2622 & 3.8462 & 3.8462 & 1 & 1.0591 & 0.3250 \\
0.2552 & 3.8462 & 3.8462 & 0.9442 & 1 & 0.3250 \\
0.3670 & 2.8514 & 2.3079 & 3.0769 & 3.0769 & 1
\end{array}\right) \\
C I_{Y_{1}}=0.082 R I_{Y_{1}}=1.24 C R_{\Upsilon_{1}}=0.066<0.10
\end{gathered}
$$


Consequently, all the hierarchical weights prove acceptable and are collected as follows:

$$
\begin{aligned}
& w_{X}=(0.40,0.40,0.20)^{T} \\
& w_{\Upsilon_{1}}=(0.45,0.07,0.07,0.12,0.12,0.17)^{T} \\
& w_{\Upsilon_{2}}=(0.24,0.62,0.14)^{T} \\
& w_{\Upsilon_{3}}=(0.25,0.50,0.25)^{T}
\end{aligned}
$$

\subsubsection{Performance Coefficient Determination}

\begin{tabular}{|c|c|c|c|c|c|c|c|c|c|c|c|c|c|}
\hline Layer & Item & & & & & & archic & 1 Wei & & & & & \\
\hline \multirow{2}{*}{ Criterion } & $Y$ & $Y_{1}$ & & & & & & $Y_{2}$ & & & $Y_{3}$ & & \\
\hline & $w$ & 0.40 & & & & & & 0.40 & & & 0.20 & & \\
\hline \multirow{2}{*}{ Index } & Z & $Z_{1}$ & $Z_{2}$ & $Z_{3}$ & $Z_{4}$ & $Z_{5}$ & $Z_{6}$ & $Z_{7}$ & $Z_{8}$ & $Z_{9}$ & $Z_{10}$ & $Z_{11}$ & $Z_{12}$ \\
\hline & $w$ & 0.45 & 0.07 & 0.07 & 0.12 & 0.12 & 0.17 & 0.24 & 0.62 & 0.14 & 0.25 & 0.50 & 0.25 \\
\hline \multirow{2}{*}{ Plan A } & $I$ & 85 & 80 & 80 & 90 & 90 & 85 & 80 & 85 & 80 & 90 & 90 & 90 \\
\hline & $P$ & 0.854 & & & & & & & & & & & \\
\hline \multirow{2}{*}{ Plan B } & $I$ & 90 & 90 & 85 & 85 & 80 & 85 & 90 & 80 & 75 & 80 & 80 & 80 \\
\hline & $P$ & 0.835 & & & & & & & & & & & \\
\hline
\end{tabular}

Referring to Equation (24) and gained hierarchical weights, the performance coefficient of each replacement plan can be determined and illustrated, as Table 14 shows.

Table 14. Performance coefficients determination of replacement plans.

Ultimately, plan A with the higher performance coefficient of 0.854 will be adopted to guide the BECI replacement, which implies that the MA modular type BECI will be selected instead of the SC comb plate type.

\section{Comparative Experimental Analysis}

A set of comparative experiments were designed and performed to verify the accuracy and effectiveness of the proposed hybrid chaotic whale optimization algorithm for solving the $\min L$ in the case study. The basic particle swarm optimization (PSO) algorithm and standard whale optimization algorithm (WOA) are introduced as the competitive algorithms, where the former is a classical representative meta-heuristic algorithm and the latter is an emerging prevailing one. The evolution curves of the fitness value for $\min L$ are illustrated in Figure 9, where the superiority of HCWOA with both considerable convergence speed and excellent convergence accuracy for solving $\min L$ is demonstrated.

In the phase of population initialization, the Tent chaotic mapping strategy is introduced to HCWOA, which achieved the least fitness value at the first iteration compared with other rivals and led to a fast convergence. Significantly, in the period of iteration 200 to 300, the HCWOA hybridized with the Lévy flight strategy never failed to keep the momentum in perusing further convergence, while the standard WOA was convergent, which demonstrates that the Lévy flight strategy is capable of preventing WOA from trapping in local optimum and improving the convergence accuracy substantially. 


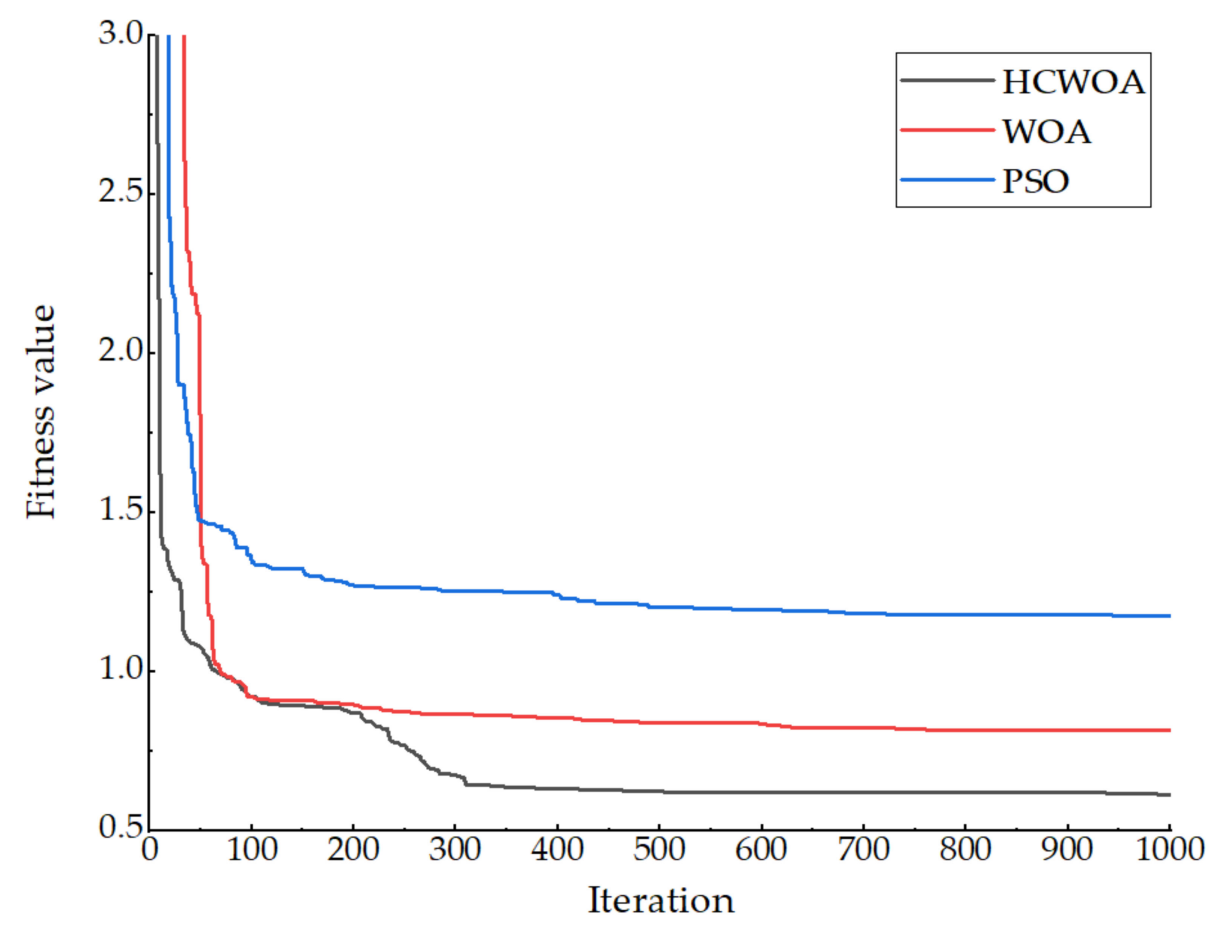

Figure 9. Evolution curves of the fitness value for $\min L$.

Corresponding to the optimal fitness value of each optimization algorithm, the modified comparison matrices are generated automatically, and the results of consistency tests are gained as follows:

$$
\begin{aligned}
& Y_{1, \mathrm{HCWOA}}=\left(\begin{array}{cccccc}
1 & 6.1514 & 6.1457 & 3.8134 & 3.9181 & 2.7247 \\
0.1626 & 1 & 0.9832 & 0.2600 & 0.2600 & 0.3507 \\
0.1627 & 1.0170 & 1 & 0.2600 & 0.2600 & 0.4333 \\
0.2622 & 3.8462 & 3.8462 & 1 & 1.0591 & 0.3250 \\
0.2552 & 3.8462 & 3.8462 & 0.9442 & 1 & 0.3250 \\
0.3670 & 2.8514 & 2.3079 & 3.0769 & 3.0769 & 1
\end{array}\right) \\
& C I_{Y_{1}, \mathrm{HCWOA}}=0.082 R I_{Y_{1}, \mathrm{HCWOA}}=1.24 \quad C R_{\mathrm{Y}_{1}, \mathrm{HCWOA}}=0.066<0.10 \\
& Y_{1, \text { WOA }}=\left(\begin{array}{cccccc}
1 & 6.1156 & 6.1009 & 4.1316 & 3.7958 & 2.8451 \\
0.1635 & 1 & 1.1734 & 0.2056 & 0.2030 & 0.3003 \\
0.1639 & 0.8522 & 1 & 0.2047 & 0.2355 & 0.3941 \\
0.2420 & 4.8638 & 4.8852 & 1 & 0.9961 & 0.3250 \\
0.2634 & 4.9261 & 4.2463 & 1.0039 & 1 & 0.2854 \\
0.3515 & 3.3300 & 2.5374 & 3.0769 & 3.5039 & 1
\end{array}\right) \\
& C I_{Y_{1}, \mathrm{WOA}}=0.105 R I_{Y_{1}, \mathrm{WOA}}=1.24 \quad C R_{Y_{1}, \mathrm{WOA}}=0.085<0.10 \\
& Y_{1, \text { PSO }}=\left(\begin{array}{cccccc}
1 & 6.1623 & 6.1083 & 3.7820 & 2.8000 & 2.4107 \\
0.1623 & 1 & 0.9884 & 0.2450 & 0.2087 & 0.3278 \\
0.1637 & 1.0117 & 1 & 0.1982 & 0.2361 & 0.3471 \\
0.2644 & 4.0816 & 5.0454 & 1 & 0.9020 & 0.2431 \\
0.3571 & 4.7916 & 4.2355 & 1.1086 & 1 & 0.2459 \\
0.4148 & 3.0506 & 2.8810 & 4.1135 & 4.0667 & 1
\end{array}\right) \\
& C I_{Y_{1}, \mathrm{PSO}}=0.112 R I_{Y_{1}, \mathrm{PSO}}=1.24 \quad C R_{Y_{1}, \mathrm{PSO}}=0.090<0.10
\end{aligned}
$$


In conclusion, the results of comparative experimental analysis are summarized and expressed in Table 15, where the superiority and effectiveness of the proposed HCWOA for solving $\min L$ and modifying inconsistent comparison matrix are verified by comparing with the standard WOA and the basic PSO. The HCWOA optimization algorithm with the best optimal fitness value proves efficient to reduce the consistency ratio of initial matrix to $60 \%$, which is capable of assisting the initial matrix to pass the consistency test automatically and efficiently. Compared with the standard WOA, the HCWOA proposed in this research under the assistance of the Tent chaotic mapping strategy and the Lévy flight strategy proves capable of being equipped with excellent convergence accuracy, speed, and stability, even to handle a large-scale global optimization problem. Furthermore, the parameters $\mu$ and $k$ in Equation (11) can be adjusted appropriately when the better consistency of the comparison matrix is required or more initial information of the matrix is necessary to be reserved.

Table 15. Result of comparative experimental analysis.

\begin{tabular}{ccccc}
\hline \multirow{2}{*}{ Item } & \multirow{2}{*}{ Initial Matrix } & \multicolumn{3}{c}{ Optimization Algorithm } \\
\cline { 3 - 5 } & & HCWOA & WOA & PSO \\
\hline Optimal fitness value & $/$ & 0.6131 & 0.8166 & 1.1767 \\
Consistency ratio & 0.110 & 0.066 & 0.085 & 0.090 \\
\hline
\end{tabular}

\section{Summary and Conclusions}

In this research, a BECI technical condition assessment approach, which contains specific on-site inspection regulations with both qualitative and quantitative descriptions, is proposed, and an improved BECI replacement plan decision system is constructed under the assistance of the HCWOA. In the first stage of the decision process, on-site inspection was conducted on the target BECI, which were hierarchically classified according to various installation types, and the inspection index evaluation was performed to provide the basis of progressive assessment calculation. A BECI technical condition assessment software was developed based on the MATLAB platform by utilizing the proposed assessment approach and algorithm, where the automation of assessment could be realized and "whether or not to replace" was also determined. In the second stage, 12 kinds of design, construction, and management requirements were introduced as the criteria, where the hierarchy model for selecting the performance-based optimal replacement plan was constructed via AHP. The HCWOA was designed and employed to modify and handle the established mathematical model, where the optimal plan can be selected precisely. The case study demonstrates that the BECI replacement decision system improved by this research proves reasonable and feasible. Simultaneously, the comparative experiments verify the superiority and effectiveness of the developed HCWOA for modifying and solving the proposed mathematical problem, where the consistency ratio of initial matrix is capable of being reduced to $60 \%$ and pass the consistency test effectively. The improved decision system proves to be a reliable DM tool in the field of bridge $\mathrm{O}$ and $\mathrm{M}$.

Based on the findings and compared with a traditional decision system, the improved BECI replacement decision system established in this article cannot only achieve the standardization of BECI on-site inspection but also attain the automations of both the technical condition assessment and the replacement plan selection. Accordingly, both the project managers and on-site inspectors are entitled to participate in the decisionmaking process directly, which reduces the $\mathrm{O}$ and $\mathrm{M}$ cost effectively and proves the most significant improvement. In conclusion, this research not only improves and automates the processes of DM system, but also emphasizes the centrality of people themselves. The efficiency improvement and resource conservation of DM are pursued for those who are the decision makers themselves; hence, every member in the system has the opportunity to be empowered and motivated to make decisions. 
Notably, only the performances of BECI are considered in the process of replacement plan selection, while the economic cost during the operation period is excluded. Consequently, in order to enhance the integrity of improved system, further research should be conducted on the selection of economic-based optimal replacement plan of BECI. In addition, the forecasting of traffic and the environmental elements such as weather and temperature, which could be variable in the near future, should also be taken into consideration as crucial indices in the DM model, where the sensors arranged inside the construction could help in data monitoring and collection. Furthermore, the developed HCWOA is only performed to handle the mathematical model in this research, which could also be extended to higher-dimensional or multi-objective optimization problems.

Author Contributions: Conceptualization, Z.X. and M.H.; methodology, Z.X. and M.H.; software, Z.X. and M.H.; validation, M.H.; formal analysis, Z.X.; investigation, Z.X. and M.H.; resources, M.H.; data curation, Z.X.; writing-original draft preparation, Z.X.; writing-review and editing, M.H. and Z.X.; visualization, Z.X. and M.H.; supervision, M.H.; project administration, M.H.; funding acquisition, M.H. and Z.X. Both authors have read and agreed to the published version of the manuscript.

Funding: The paper is funded by the 2017 Transportation Technological Progress Plan Project of Anhui Province, China (Rapid replacement techniques of expansion and contraction installations for highway bridges) and the Graduate Innovative Fund of Wuhan Institute of Technology (CX2020113).

Institutional Review Board Statement: Not applicable.

Informed Consent Statement: Not applicable.

Data Availability Statement: The data used to support the findings of this study are available from the corresponding author upon request.

Conflicts of Interest: The authors declare that there is no conflict of interest regarding the publication.

\section{References}

1. Ministry of Transport of the People's Republic of China (MOT). General Technical Requirements of Expansion and Contraction Installation for Highway Bridge; China Communications Press: Beijing, China, 2016. (In Chinese)

2. Huang, M.; Xu, Z.; Li, L.; Lei, Y. Construction and Application of Bridge Expansion and Contraction Installation Replacement Decision System Based on the Analytic Hierarchy Process. Materials 2020, 13, 4177. [CrossRef]

3. Saaty, T.L. How to make a decision: The Analytic Hierarchy Process. Eur. J. Oper. Res. 1990, 48, 9-26. [CrossRef]

4. Harputlugil, T.; Prins, M.A.; Topcu, I. Conceptual framework for potential implementations of multi criteria decision making (MCDM) methods for design quality assessment. In Proceedings of the Management and Innovation for a Sustainable Built Environment, CIB International Conference, Amsterdam, The Netherlands, 20-23 June 2011.

5. Vidal, L.A.; Marle, F.; Bocquet, J.C. Using a Delphi process and the Analytic Hierarchy Process (AHP) to evaluate the complexity of projects. Expert Syst. Appl. 2011, 38, 5388-5405. [CrossRef]

6. Liu, X.; Pan, Y.; Xu, Y.; Yu, S. Least square completion and inconsistency repair methods for additively consistent fuzzy preference relations. Fuzzy Set. Syst. 2012, 198, 1-19. [CrossRef]

7. Ahmed, F.; Kilic, K. Fuzzy Analytic Hierarchy Process: A performance analysis of various algorithms. Fuzzy Set. Syst. 2019, 362, 110-128. [CrossRef]

8. Wang, H.; Kou, G.; Peng, Y. An Iterative Algorithm to Derive Priority from Large-Scale Sparse Pairwise Comparison Matrix. IEEE Trans. Syst. Man Cybern. Syst. 2021. [CrossRef]

9. Yang, I.; Wang, W.; Yang, T. Automatic repair of inconsistent pairwise weighting matrices in analytic hierarchy process. Automat. Constr. 2012, 22, 290-297. [CrossRef]

10. Lin, C.; Wang, W.; Yu, W. Improving AHP for construction with an adaptive AHP approach $\left(\mathrm{A}^{3}\right)$. Automat. Constr. 2008, 17, 180-187. [CrossRef]

11. Girsang, A.S.; Tsai, C.; Yang, C. Ant algorithm for modifying an inconsistent pairwise weighting matrix in an analytic hierarchy process. Neural Comput. Appl. 2015, 26, 313-327. [CrossRef]

12. Huang, M.; Cheng, S.; Zhang, H.; Mustafa, G.; Lu, H. Structural Damage Identification under Temperature Variations Based on PSO-CS Hybrid Algorithm. Int. J. Struct. Stab. Dyn. 2019, 19, 1950139. [CrossRef]

13. Huang, M.; Li, X.; Lei, Y.; Gu, J. Structural damage identification based on modal frequency strain energy assurance criterion and flexibility using enhanced Moth-Flame optimization. Structures 2020, 28, 1119-1136. [CrossRef]

14. Huang, M.; Mustafa, G.; Zhu, H. Vibration-Based Structural Damage Identification under Varying Temperature Effects. J. Aerosp. Eng. 2018, 31, 04018014. [CrossRef] 
15. Mirjalili, S.; Lewis, A. The Whale Optimization Algorithm. Adv. Eng. Softw. 2016, 95, 51-67. [CrossRef]

16. Gharehchopogh, F.S.; Gholizadeh, H. A comprehensive survey: Whale Optimization Algorithm and its applications. Swarm. Evol. Comput. 2019, 48, 1-24. [CrossRef]

17. Xiong, G.; Zhang, J.; Shi, D.; He, Y. Parameter extraction of solar photovoltaic models using an improved whale optimization algorithm. Energ. Convers. Manag. 2018, 174, 388-405. [CrossRef]

18. Moodi, Y.; Mousavi, S.R.; Ghavidel, A.; Sohrabi, M.R.; Rashki, M. Using Response Surface Methodology and providing a modified model using whale algorithm for estimating the compressive strength of columns confined with FRP sheets. Constr. Build. Mater. 2018, 183, 163-170. [CrossRef]

19. Mafarjaa, M.M.; Mirjalili, S. Hybrid Whale Optimization Algorithm with simulated annealing for feature selection. Neurocomputing 2017, 260, 302-312. [CrossRef]

20. Reddy, M.P.; Babu, M.R. Implementing self adaptiveness in whale optimization for cluster head section in Internet of Things. Cluster. Comput. 2019, 22, 1361-1372. [CrossRef]

21. Aziz, M.A.; Ewees, A.A.; Hassaniend, A.E. Whale Optimization Algorithm and Moth-Flame Optimization for multilevel thresholding image segmentation. Expert Syst. Appl. 2017, 83, 242-256. [CrossRef]

22. Srivastava, A.; Das, D.K.; Rai, A.; Raj, R. Parameter Estimation of a Permanent Magnet Synchronous Motor using Whale Optimization Algorithm. In Proceedings of the 2018 Recent Advances on Engineering, Technology and Computational Sciences (RAETCS), Allahabad, India, 6-8 February 2018; pp. 1-6.

23. Zhang, X.; Liu, Z.; Miao, Q.; Wang, L. Bearing fault diagnosis using a whale optimization algorithm-optimized orthogonal matching pursuit with a combined time-frequency atom dictionary. Mech. Syst. Signal Process. 2018, 107, 29-42. [CrossRef]

24. Dao, T.; Pan, T.; Pan, J. A Multi-Objective Optimal Mobile Robot Path Planning Based on Whale Optimization Algorithm. In Proceedings of the 2016 IEEE 13th International Conference on Signal Processing (ICSP), Chengdu, China, 6-10 November 2016; pp. 337-342.

25. Horng, M.; Dao, T.; Shieh, C.; Nguyen, T. A Multi-Objective Optimal Vehicle Fuel Consumption Based on Whale Optimization Algorithm. In Advances in Intelligent Information Hiding and Multimedia Signal Processing; Springer: Cham, Switzerland, 2017; pp. 371-380.

26. Khalilpourazari, S.; Pasandideh, S.H.; Ghodratnama, A. Robust possibilistic programming for multi-item EOQ model with defective supply batches: Whale Optimization and Water Cycle Algorithms. Neural Comput. Appl. 2019, 31, 6587-6614. [CrossRef]

27. Sreenu, K.; Sreelatha, M. W-Scheduler: Whale optimization for task scheduling in cloud computing. Cluster Comput. 2019, 22, 1087-1098. [CrossRef]

28. Huang, M.; Cheng, X.; Lei, Y. Structural damage identification based on substructure method and improved whale optimization algorithm. J. Civ. Struct. Health Monit. 2021, 11, 351-380. [CrossRef]

29. Kaur, G.; Arora, S. Chaotic Whale Optimization Algorithm. J. Comput. Des. Eng. 2018, 5, 275-284. [CrossRef]

30. Yang, X.S.; Suash, D. Cuckoo search via levy flights. In World Congress Nature Biologically Inspired Computer (NaBIC); IEEE Publication: New York, NY, USA, 2009; pp. 210-214.

31. Kamaruzaman, A.F.; Zain, A.M.; Yusuf, S.M.; Udin, A. Levy flight algorithm for optimization problems-A literature review. Appl. Mech. Mater. 2013, 421, 496-501. [CrossRef]

32. Abdel-Basset, M.; El-Shahat, D.; Sangaiah, A.K. A modified nature inspired meta-heuristic whale optimization algorithm for solving 0-1 knapsack problem. Int. J. Mach. Learn. Cyb. 2019, 10, 495-514. [CrossRef]

33. Abdel-Basset, M.; Abdle-Fatah, L.; Sangaiah, A.K. An improved Lévy based whale optimization algorithm for bandwidth-efficient virtual machine placement in cloud computing environment. Cluster Comput. 2019, 22, 8319-8334. [CrossRef]

34. Sun, Y.; Wang, X.; Chen, Y.; Liu, Z. A modified whale optimization algorithm for large-scale global optimization problems. Expert Syst. Appl. 2018, 114, 563-577. [CrossRef]

35. Ministry of Transport of the People's Republic of China (MOT). Highway Performance Assessment Standards; China Communications Press: Beijing, China, 2018. (In Chinese)

36. Ministry of Transport of the People's Republic of China (MOT). Standards for Technical Condition Evaluation of Highway Bridges; China Communications Press: Beijing, China, 2011. (In Chinese)

37. Ocampoa, L.; Ebisab, J.A.; Ombeb, J.; Escotob, M.G. Sustainable ecotourism indicators with fuzzy Delphi method-A Philippine perspective. Ecol. Indic. 2018, 93, 874-888. [CrossRef]

38. Cao, W.D.; Wang, A.T.; Yu, D.S.; Liu, S.T.; Hou, W. Establishment and implementation of an asphalt pavement recycling decision system based on the analytic hierarchy process. Resour. Conserv. Recycl. 2019, 149, 738-749. [CrossRef]

39. Gandomi, A.H.; Yang, X.-S.; Talatahari, S.; Alavi, A.H. Firefly algorithm with chaos. Commun. Nonlinear Sci. 2013, 18, 89-98. [CrossRef]

40. Liu, M.; Yao, X.; Li, Y. Hybrid whale optimization algorithm enhanced with Lévy flight and differential evolution for job shop scheduling problems. Appl. Soft Comput. 2019, 87, 105954. [CrossRef]

41. Mantegna, R.N. Fast, accurate algorithm for numerical simulation of Lévy stable stochastic processes. Phys. Rev. E 1994, $49,4677$. [CrossRef] [PubMed] 